\title{
Entwicklungsgeschichtliche Untersuchungen an zentrischen Diatomeen IV.
}

\author{
Die Planktondiatomee Stepbanopyxis turris - ihre Behandlung und \\ Entwicklungsgeschichte ${ }^{1}$
}

\author{
Hans A. von Stosch und Gerhard Drebes ${ }^{2}$ \\ Botanisches Institut der Universität Marburg
}

\begin{abstract}
Ontogenetic investigations on centric diatoms IV. The planktonic diatom Stephanopyxis turris - its treatment and life history. This paper presents a detailed account of the life cycle, development and cellular mechanics of the centric diatom $S$. turris. Special attention is paid to culture methods, nutritional requirements and the mechanism of vegetative cell enlargement. Instructions are outlined for experimental manipulations of developmental features. Various aspects of development are treated in details, e. g. cellular structures, cell division and morphogenesis, development and germination of resting spores, differentiation of gametangia (spermatogonangia, spermatogonia and oogonia), meiosis in the gametocytes, fertilization and auxospore differentiation (including the formation of the "rejuvenated" first cell and the accompanying metagamic mitoses). S. turris has one-egged oogonia. Its spermatogonangia develop their spermatogonia according to the Biddulpbia granulata-type and their spermiums according to the Melosira-type (Fig. 18). Two new termini, i. e. "heterovalvate cytokinesis" and "depauperizing mitosis" are introduced (p. 232, p. 238). Among the more important results are observations on karyokinesis in vivo, meiosis and karyogamy, and on the peculiar process of destruction of supernumerary nuclei following each karyokinesis in the oocyte, and later in the young auxospore. Relations between osmotic cell rhythms, karyokinetic cycle and morphogenesis are discussed at the end of the paper.
\end{abstract}

\section{EINLEITUNG}

Bei den bisherigen Arbeiten dieser Serie (v. STosch 1951, 1956, 1958) war lediglich darauf Wert gelegt worden, die kritischen Punkte im Lebenszyklus der behandelten Centrales klarzustellen; nach den bis 1950 vorliegenden Kenntnissen mußten dies die mit der Vorbereitung und dem Ablaufen der Sexualvorgänge verbundenen sein. Von der vegetativen Entwicklung wurde nur das zum Verständnis jener Dinge unbedingt Erforderliche gebracht und daher bisher weder die Zellteilung eingehender geschildert, noch die Weiterentwidklung der Zygote. Uber die Bildung der Dauersporen von Diatomeen berichteten wenige, von ihrer Keimung nur ein Untersucher.

1 Herrn Professor Dr. Adole BÜCKMANn zum 65. Geburtstag in Verehrung gewidmet.

2 Diese Studie enthält Teile der Dissertation von G. DREBEs. 
Da der Formwechsel der Diatomeen bisher nur für die Pennaten (Gertler 1932, 1957) eine Bearbeitung erfuhr, die Daten für die Centrales aber in der Literatur weit verstreut sind, da sich ferner über die Entwicklungsgeschichte der zentrischen Diatomeen heute dank des durch die Verbesserung der Kulturmethoden ermöglichten Zusammenwirkens von langdauernder Lebendbeobachtung und cytologischen Verfahren weit mehr aussagen läßt als früher, schien es bei dem steigenden Interesse am marinen Plankton an der Zeit, dem Morphologen wie dem Physiologen und Ókologen die ausführliche Schilderung eines "Standardobjektes" aus dieser repräsentativen Gruppe der Schwebepflanzen in allen seinen Entwicklungsvorgängen an die Hand zu geben. Wir wählten Stepbanopyxis turris, einen Organismus, welcher infolge der Größe und des Baues seiner Zellen und deren Vereinigung in Kolonien sämtliche Phasen seines Gestaltwechsels der direkten, kontinuierlichen Beobachtung zugänglich macht, und zwar bis auf das Niveau der Kernvorgänge herab. Da diese Diatomee leicht kultiviert werden kann und eine relativ geringe Generationsdauer besitzt, eignet sie sich besonders als Demonstrationsobjekt, das nicht nur Zustände feststellen, sondern Vorgänge unter dem Aspekt der in vielen Punkten eigenartigen Zellmechanik der Diatomeen verfolgen läßt. Dic Arbeit verfolgt weiterhin den didaktischen $Z$ weck, Leitfaden für Untersuchung an einer Kieselalge zu sein, bei welcher Zellteilung, Dauersporenbildung und -keimung, Differenzierung der Spermatogonien, Meiosis in männlichen und weiblichen Gametocyten (einschließlich der eigenartigen Konkurrenzvorgänge um das Überleben der Eikerne), Befruchtung und Auxosporenbildung (mit dem von GEITLER 1953 a, b entdeckten, an die Schalenbildung gekoppelten metagamen Mitosen) beim gleichen Objekt und im Leben studiert werden können. Stephanopyxis wird wegen dieser Eigenschaften seit einigen Jahren im Marburger Großpraktikum routinemäßig untersucht. Gleichzeitig führen wir eine für viele Fragestellungen zytologischer und physiologischer Art geeignete Planktondiatomee als Laboratoriumsobjekt ein. Diese Diatomee besitzt den Vorteil, daß sie in ihrer Zellgröße ohne Anderung des Genotypus manipuliert und daher für das Experiment in beliebigen Zellbreiten zur Verfügung gestellt werden kann. Dieser Umstand ist für das experimentelle Arbeiten mit Diatomeen wichtig, ja eigentlich unumgänglich (S. 215). Wir schildern daher aud die Technik von Kultur und Lebendbeobachtung. Die Entwicklungsphysiologie der Auslösungsvorgänge für Dauersporen- und Sexualzellen soll dagegen nur insofern dargestellt werden, als sie für eine "rezeptmäßige" Behandlung des Objelsts erforderlich erscheint.

\section{DAS OBJEKT}

Stephanopyxis turris (GREv. et ARN.) RALFs ist eine in den temperierten Meeren verbreitete, aber nicht Massenproduktionen bildende, in Linearkolonien auftretende Planktondiatomee, welche dem nereitischen Bereich, also den Wassern der Schelfmeere, angehört; darauf deutet auch das Vorkommen von Dauersporen hin.

Der von uns untersuchte Stamm wurde 1953 in List auf Sylt (Nordsee) isoliert und seit dieser Zeit im Laboratorium kultiviert. Die Diatomee hat bei hinreichendem Lichtgenuß (etwa $1000 \mathrm{Lux} / 16-\mathrm{Std}$-- Tag) und bei $15^{\circ} \mathrm{C}$ eine Generationsdauer von 
Zellteilung zu Zellteilung von 24 Stunden; unter erhöhter Temperatur $\left(21^{\circ} \mathrm{C}\right)$ und entsprechender Beleuchtung (etwa 4000 Lux/14-Std.-Tag) werden sogar zwei Teilungen innerhalb dieser Zeit durchgeführt. Da Diatomeen, bedingt durch den Schachtelbau ihrer Membran, im Laufe der Zellvermehrung an Zellbreite verlieren (MacDonaldPritzersches Wachstumsgesetz), ist bei ihnen in der Natur ein Prozeß der Zellvergrößerung eingeschaltet, der bei zentrischen wie pennaten Diatomeen gewöhnlich durch einen Sexualvorgang eingeleitet wird; bei den erstgenannten ist dieser eine Oogamie. Die Gametenkerne sind in allen Fällen direkte Produkte der Meiosis. Die vergxößerte Zelle, die Auxospore, geht aus der Zygote hervor, welche dabei besondere und charakteristische Wachstums- und Gestaltungsprozesse durchmacht. Aus dem Gesagten erhellt, daß es sich um den Sexualvorgang eines Diplonten handelt. Eine der freien Natur entnommene, diploide Zelle wird auch, wenn sie von einer monözischen Art $^{3}$ stammt, im allgemeinen heterozygot sein und daher in der Meiosis grundsätzlich ungleiche Gameten und demzufolge vom Genotypus der Mutterzelle abweichende Zygoten liefern. Diese Erwartung fanden wir auch bei Stephanopyxis (ähnliche Beobachtungen an Sceletonema; Droor 1962) erfüllt, und zwar insofern, als unter 40 isolierten Auxosporenklonen in dem für den Ausgangsstamm geeigneten Medium nur 7 über die zweite Tochterkultur hinaus teilungsfähig waren. Die übrigen starben nach mehr oder weniger zahlreichen Teilungen ab, besaßen also vermutlich genetische Defektkombinationen. Auch die 7 übriggebliebenen Stämme zeigten Unterschiede in der Neigung, Dauersporen zu bilden, sowie in der Teilungsrate. Da man aber Wert darauf legen wird, mit genetisch einheitlichem Material zu experimentieren, ist die Möglichkeit, die Zellbreiten auf nicht sexuellem Wege (nämlich durch einen Akt "vegetativer Zellvergrößerung") zu erhöhen, welche bei Stephanopyxis wie bei manchen anderen Diatomeen existiert (v. STоsсн 1965), von besonderem Wert. Dieser Vorgang, auf den wir später noch eingehen werden, erlaubte es, den Organismus über 10 Jahre genetisch unverändert zu halten und zu jedem Zeitpunkt innerhalb des arteigenen Größenberciches beliebige Zellengrößen zur Verfügung zu haben.

\section{METHODEN}

\section{Handbabung in der Kultur}

\section{Kulturmethode}

Die Alge wird in einem Medium kultiviert, das im Grunde auf ein Rezept von SCHREIBER (1928) zurückgeht, aber eine Reihe weiterer Nährstoffe sowie den Chelator Athylendiamintetraessigsäure in Form seines Dinatriumsalzes $\left(\mathrm{Na}_{2} \mathrm{EDTA} \cdot 2 \mathrm{H}_{2} \mathrm{O}\right)$ enthält (Tab. 1).

Die Lösung wird aus Stammlösungen zusammenpipettiert und in einem Erlenmeyerkolben mit aufgesetzter Glaskappe mittels eines Spiegelbrenners (Firma BüHLER, Tübingen) bis zum beginnenden Sieden erhitzt. Darauf wird sie in bei $120^{\circ} \mathrm{C}$ trocken

3 Diözisch sind nach derzeitiger Kenntnis nur zwei pennate Diatomeen, Rbabdonema adriaticum (v. STosch 1958) und Grammatophora marina (unpubl.). 
Tabelle 1

Kulturmedium für Stephanopyxis turris

\begin{tabular}{|lcccc|}
\hline Seewasser & $1020 \mathrm{~g}$ & & & \\
\hline $\mathrm{NaNO}_{3}$ & $42,5 \mathrm{mg}$ & 500 & $\mu \mathrm{mol}$ & $7000 \mu \mathrm{g} \mathrm{N}$ \\
$\mathrm{Na}_{2} \mathrm{HPO}_{4} \cdot 12 \mathrm{H} \mathrm{H}$ & $10,75 \mathrm{mg}$ & 30 & $\mu \mathrm{mol}$ & $930 \mu \mathrm{g}$ \\
$\mathrm{FeSO}_{4} \cdot 7 \mathrm{H}_{2} \mathrm{O}$ & $278 \mathrm{~g}$ & 1 & $\mu \mathrm{mol}$ & $55,8 \mu \mathrm{g} \mathrm{Fe}$ \\
$\mathrm{MnCl}_{2} \cdot 4 \mathrm{H}_{2} \mathrm{O}$ & $19,8 \mu \mathrm{g}$ & $0,1 \mu \mathrm{mol}$ & $5,9 \mu \mathrm{g} \mathrm{Ma}$ \\
$\mathrm{SiO}_{2}$ & $12 \mathrm{mg}$ & 200 & $\mu \mathrm{mol}$ & $5,6 \mu \mathrm{g} \mathrm{Si}$ \\
$\mathrm{Na}_{2} \mathrm{EDTA} \cdot 2 \mathrm{H}_{2} \mathrm{O}$ & $3,72 \mathrm{mg}$ & $10 \mu, \mu \mathrm{mol}$ & \\
Cobalamin & $0,7 \mu \mathrm{g}$ & $0,005 \mu \mathrm{mol}$ & \\
\hline
\end{tabular}

sterilisierte Petrischalen (meist $6 \mathrm{~cm} \varnothing$, mit Glasplatten abgedeckt; Jenaer Geräteglas 20) eingegossen. Die Beimpfung geschieht mit Hilfe einer "Mundpipette"; diese ist am breiten Ende mit dünnem Gummischlauch zum Aufsaugen und Ausblasen versehen und ihre feine Offnung auf einen Durchmesser gebracht, der denjenigen der zu pipettierenden Zellen um nicht mehr als das Doppelte oder Dreifache übertreffen sollte. Für Experimente, etwa über Ernährung, können die Zellen ohne Mühe abgezählt $(4,8,16,32)$ eingesetzt werden. Die Kulturen werden in temperaturkonstanten Räumen auf weißer Unterlage gehalten und mit Leuchtstoffröhren (Type Osram L $40 \mathrm{~W} / 35$; 16-Std.-Tag bei $15^{\circ} \mathrm{C}, 14-\mathrm{Std}$.-Tag bei $21^{\circ} \mathrm{C}$ ) beleuchtet. Die angegebenen Lichtwerte beziehen sich auf „räumliche Lux“ (R-Lux), gemessen mit einer SpezialPhoto-Zelle, die den gesamten Raumwinkel von $4 \pi$ aufnimmt; mit einer gewöhnlichen, ebenen Photozelle würde man etwa die halben Werte bekommen. Stammkulturen können bei $15^{\circ} \mathrm{C}$ und 150 bis 200 Lux gehalten werden. Die in der Arbeit angegebenen Tageszeiten sind auf einen zu 12 Uhr Ortszeit symmetrischen Lichtwechsel bezogen; in Wirklichkeit war der experimentelle Tag um 4 Stunden bei $16^{\circ} \mathrm{C}$, um 3 Stunden bei $21^{\circ} \mathrm{C}$ abendwärts gegen den letzteren verschoben. Die Kulturen sind bakterienhaltig, weil eine Methodik, welche die gewünschten Beobachtungen unter der Kautele der Sterilität zuließe, zu umständlich würde. Auch die Verwendung natürlichen. Seewassers (Nordseewasser, das in 50-Liter-Ballons von der Litoralstation der Biologischen Anstalt Helgoland aus List unfiltriert bezogen, bei uns durch Filtrierpapier mit einer aufgeschwemmten Kieselgurschicht gesaugt und danach aufbewahrt wird) ist ein Kompromiß an die experimentelle Zweckmäßigkeit. Provasoli (Provasoli et al. 1957) hat unseren Stamm von Stephanopyxis jedoch in bakterienfreie Kultur in vollsynthetischem Medium genommen und das Hinreichen wie die Notwendigkeit (mündliche Mitteilung) des zugesetzten Vitamins bestätigt.

\section{Diskussion der Nährstoffansprüche}

Schreiten wir zur Besprechung der Einzelzugaben der Nährlösung, so sei zunächst daran erinnert, daß eine Reihe der auf dem Lande gelegentlich begrenzenden Nährstoffe im Seewasser in genügender Menge vorhanden sind (HARver 1960), wie Kalium, Magnesium, Calcium, Sulfat, Bor und wohl Zink. Daher fungieren im Wasser der Nordsee Nitrat und Phosphat (Schreiber 1928) als die beiden ersten Minimumnährstoffe für Kieselalgen. Ihr molares Verhältnis in der Nährlösung entspricht etwa 
demjenigen in der See im Durchschnitt und auch dem mittleren Bedarf autotropher Pflanzen (HARvey 1960). Thr Fehlen, wie auch der Mangel an E is en führten nach Herabsetzung und schließlichem Schwinden der Teilungen zu partiellem Ausbleichen der Chromatophoren und, da die Photosynthese noch weiter geht, zur Anhäufung des Speicher-Kohlehydrates der Diatomeen, des Leucosins (neuerdings wegen der chemischen Ahnlichkeit zum Laminarin der Braunalgen, BEATtIE et al. 1961, auch Chrysolaminarin genannt), daneben werden geringe Mengen Fett in Tröpfchen eingelagert. Leucosin ist wasserlöslich und verleiht der Vakuolenflüssigkeit einen erhöhten Brechungsindex. Die Zellen bekommen dadurch die Eigenschaft einer Zylinder- (Sammel-) linse, was sich am Auftreten einer Lichtlinie, der Brennlinie der Linse, beim Heben des Tubus erkennen läßt. Im übrigen wird N-Mangel lange und ohne tiefere Schäden ertragen, während P-Mangel hier, im Gegensatz zu anderen Diatomeen, rasch zu schweren Beeinträchtigungen und einem Absterben der Zellen führt.

Düngt man Seewasser mit Nitrat und Phosphat, so wird Stephanopyxis trotz ihrer relativ leichten und schwach verkieselten Schalen nicht mit der im Meerwasser vorhandenen und der von Glas zusätzlich abgegebenen Kieselsäure auskommen, sondern die Kultur beginnt nunmehr, an Kieselsäuremangel zu leiden. Die notwendige Kieselsäure wird von uns in Form des $0,6 \%$ Sols zugesetzt. Weniger zu empfehlen ist das sonst (z. B. Provasoli et al. 1957) übliche Dinatriumsalz der Säure. Da nämlich die Alkalinität des Nordseewassers rund $2000 \mu$ Val OH-Ionen im Liter beträgt, würde bereits Silikat in einer unserem Rezept entsprechenden Menge einen Zuwachs von $400 \mu \mathrm{Val} \mathrm{OH}$-Ionen und damit einen merklichen Einfluß auf die Gesamtkalinität und die Wasserstoffionenkonzentration bedeuten, und diese Menge reicht nicht einmal aus, um eine optimale Ernte von Stephanopyxis zu erhalten, so daß wir die $\mathrm{SiO}_{2-}$ Dosis häufig noch erhöhen. Ein zweiter Grund für die Verwendung des Sols ${ }^{4}$ ist seine größere Reinheit. Über die Herstellung (Hydrolyse von $\mathrm{SiCl}_{4}$ oder bei geringeren Reinheitsansprüchen aus dem Silikat durch Austauscher nach Pramer 1957) wird an anderer Stelle berichtet. Die Kieselsäure wird von den Diatomeen zum Aufbau der Schale verwendet. VON STOSCH (1942), JøRGENSEN (1955) sowie LEWIN $(1957,1962)$ wiesen nach, daß der Einbau mit dem Angebot steigt und mit sich erhöhender Teilungsrate sinkt (die beiden letzten Autoren). Doch sind die Wirkungen des Kieselsäuremangels nicht durch die vordergründige Funktion ausgeschöptt. Man beobachtet nämlich, daß vielfach (v. Srosch 1942 bei Acbnanthes) in erster Linie die Zellteilung gehemmt wird, während das Plasmawachstum, die Farbstoffsynthese und die Photosynthese, demzufolge auch Leucosin- und Fettspeicherung, wenn auch gedrosselt, weitergehen. Die Kieselsäure scheint daher außer beim Schalenbau noch an wichtiger Stelle in den Metabolismus der Zelle einzugreifen; an welchem Ort ist unbekannt. Vermutlich ist es die Inkongruenz zwischen Plasmawachstum und Zellteilung, die unter protrahiertem $\mathrm{SiO}_{2}$-Mangel bei Stephanopyxis zu einer Überdehnung der Zelle (Auseinandergleiten der Schalen, Austreten von Plasma zwischen den Schalenmündungen) und

${ }_{4}$ Kolloidale Kieselsäure ist als solche nicht als $\mathrm{SiO}_{2}-Q u e l l e$ für Diatomeen geeignet, nur Orthokieselsäure (LEWIN 1955) und vielleicht weitere niedermolekulare Kieselsäuren. Doch geht kolloidale Kieselsäure bei dem $\mathrm{pH}$ von etwa 8 des Seewassers in den hier interessierenden Konzentrationen im Laufe einer Woche in niedermolekulare Formen uber (Crow \& RobINSON 1953). 
schließlich zum Tode führt. Allgemein bewirkt Kieselsäuremangel bei Diatomeen schwere Schädigungen. Kieselsäureüberschuß hingegen kann, wenn die Kieselsäure in Konzentration von 60 bis $120 \mathrm{mg}$ im Liter vorliegt, eine hemmende Wirkung auf die Schwermetallversorgung, insbesondere an Eisen (v. STOSCH 1942) ausüben, die mit der Verweilzeit der Kieselsäure in der Lösung ansteigt. Die Zellen können dann durch Eisenchlorose nahezu farblos werden und ihre Teilungen fast ganz unterdrückt sein; doch werden solche Zustände gut ertragen. Wünscht man höhere Dosierungen an Kieselsäure, so ist es daher zweckmäßig, die Zugabe beim Ansetzen der Kultur oder zu der bereits wachsenden Kultur zu machen.

Die im Rezept angegebene $\mathrm{E}$ is en menge ist vom Bedarf der Zelle aus gesehen mehr als ausreichend. Doch kann bei der leicht alkalischen Reaktion des Seewassers in $\mathrm{O}_{2}$-Gegenwart nur 3-wertiges Eisen und von diesem nur äußerst wenig in echter Lösung sein (CoOper 1948). Der Betrag wird allerdings durch den Chelator erhöht. Das Problem der Eisenversorgung in Seewassernährlösungen ist - insbesondere in Gegenwart von Chelatoren-komplex (vgl. Droop 1960). Praktisch reicht die Eisengabe des Rezeptes für Stephanopyxis aus, doch gibt es Biddulpbia regia-Rassen, die in der gleichen Zusammensetzung an Eisenmangel (Ausbleichen) leiden. Uber unterschiedliche Ansprüche von Algen in der Eisenversorgung haben Droop (1962) sowie Kramer \& RYTHER (1960) berichtet.

M a n g a n wird der Lösung zugesetzt, weil manche natürlichen Seewässer (HARvEY 1939, v. STosch 1942) Mangan-Mangelerscheinungen bei Diatomeen erzeugen, die bei Acbnanthes longipes und Stephanopyxis (weniger bei Rhabdonema adriaticum) gefährlicher Natur sind und eine Hemmung der Zellteilung bei weitergehendem Plasmazuwachs - unter Umständen begleitet von Kernteilungen. (Acbnantbes) - sowie der Leucosin- und Farbstoffproduktion hervorrufen. Bei Acbnanthes und Stephanopyxis kommt es (bei ersterer allgemein, bei letzterer seltener) zum Austreten des Protoplasten aus der Schale.

Weitere Spurenelement-Mängel haben wir bei Diatomeen unter Verwendung natürlichen Seewassers nicht nachweisen können, sie scheinen praktisch keine Rolle zu spielen.

Sehr wichtig ist dagegen für Stephanopyxis und manche andere marine Algen der Zusatz von Äthylendiamintetraessigsäure (EDTA), eines sehr wirksamen Metallkomplexers. EDTA wurde von HUTNER et al. (1950) eingefuhrt, um Schwermetalle in einer für hohe Produktionen ausreichenden Menge ohne Giftwirkungen verabreichen zu können, also als Metallpuffer. Insbesondere hat es auch einen Anteil des zugesetzten Eisens in Lösung und damit für die Zellen erreichbar zu halten. Sehr hohe EDTADosierungen (das etwa 100-fache der oben angegebenen Menge) rufen auch bei Stephanopyxis Eisenmangelsymptome, allerdings ohne Sistierung der Zellteilung hervor. Bereits WARIS (1953) wies aber auf außerordentliche, insbesondere bei geringen Besiedlungsdichten auftretende Wachstumsförderungen von Desmidiaceen durch relativ geringere Gaben von EDTA hin. Stephanopyxis führt in Seewassernährlösung ohne EDTA bei geringer Beimpfung ( $\sim 20$ Zellen / $20 \mathrm{ml}$ Lösung) nur eine Zellteilung durch und geht danach bei anhaltender Beleuchtung unter Wachstumshemmung und Zelldeformationen zugrunde. Man kann von einem Lag-Phänomen sprechen, weil, falls einmal eine Durchbrechung der Teilungsruhe stattindet, die Kulturen danach mehr 
oder weniger normal weiterwachsen. EDTA verhindert diese Lag-Erscheinungen, bei Stephanopyxis noch in $1 / 25$ der oben gegebenen Konzentration. Man könnte an die Entgiftung eines in der Nährlösung vorhandenen Schwermetalles denken, wofür die Komplexon-Natur der EDTA sprechen würde, sowie daran, daß durch einen chelierenden Harzaustauscher (Dowex A 1) perfundierte Nährlösung auch ohne EDTA lagfreies Wachstum von Stephanopyxis erlaubt. $\mathrm{Da}$ das Harz zweiwertige Metalle bindet, möchte ein solches entfernt worden sein. In gewissem Umfange ersetzt die häufig verwendete Erdabkochung, welche Huminsäuren von ebenfalls komplexierenden Eigenschaften enthält, das EDTA. Da Erdabkochung aber bei manchen Algen giftig wirkt und dazu in der, im übrigen unbekannten, Zusammensetzung wechselt, ist das synthetische Produkt vorzuziehen.

In den letzten zwei Jahrzehnten hat sich gezeigt, daß eine große Anzahl von Algenarten nicht, wie man früher glaubte, voll autotroph ist, sondern daß ihr Syntheseapparat gewisse Stoffe, kompliziertere Bausteine von Enzymen, nicht herstellen kann. Diese Hilfsstoffe müssen von außen zugeführt werden; man spricht dann von Auxotrophie. Praktisch handelt es sich bei fast allen Algen mit derartigen Bedürfnissen um die Vitamine $B_{12}$ (Cobalamin und Analoge), $B_{1}$ (Aneurin, Thiamin) oder Biotin, die in einigen Fällen einzeln, in anderen in Kombination gegeben werden müssen (Lewin 1958, Droop 1962a). Besonders häufig wird Cobala min benötigt, so auch von Stephanopyxis. Die Isolation dieses Vitamins stellt neben der Einführung der Chelatoren einen der größeren neuen Fortschritte für die Algenkultur dar; wir verdanken ihn ebenfalls dem Arbeitskreis Hutner-Provasoli. Da derartige Stoffe in sehr geringen Mengen gebraucht und sie von manchen Bakterien ausgeschieden werden, ist es strenggenommen nur in Sterilkulturen möglich, den Nachweis für ihre Notwendigkeit zu führen. Doch läßt sich die Notwendigkeit bei raschwüchsigen Arten wie Stephanopyxis auch in bakterienhaltigen Lösungen demonstrieren, insbesondere wenn das Seewasser durch Aktivkohle (1 g Aktivkohle pro Liter; aufkochen, fltrieren, dann Zusätze geben) von Vitaminresten befreit war. Überträgt man in solcher Lösung gewachsene Zellen, so kann die Produktion äußerst niedrig gehalten werden, während sie in Parallelkulturen mit Cobalaminzusatz normale Höhe erreicht.

\section{Die Technik der vegetativen Zellgrößenänderung}

$\mathrm{Da}$ Stephanopyxis einerseits nur langsam "herabteilt", also bei nicht forcierter Kultur einige Jahre braucht, um von der maximalen auf die minimale Zellgröße herabzukommen, und da, wie auf S. 211 bereits ausgeführt, andererseits die Auxosporenbildung als sexueller Prozeß genetische Neukombinationen schaff, ist es von großem Vorteil, daß diese Diatomee dank ihrer konstitionellen Eigenschaften es erlaubt, Größenänderungen sprunghaft, nichtsexuell, also unter Wahrung des Genotypus und fast nach Belieben vorzunehmen. Über diese Dinge wurde an anderer Stelle (v. STOSCH 1965) ausführlicher berichtet. Sie seien hier daher nur als eine der Methoden im Umgang mit Stephanopyxis geschildert. Die "vegetative Zellvergrößerung" geschieht in zwei Schritten. Der Protoplast wird zunächst zu partiellem Austreten aus der Schale gebracht, die sich durch Auseinandergleiten der Gürtel öffnet; dabei schwillt er über den Durchmesser der alten Schale hinaus an. Darauf wird an den neuen Oberflächen Schalen- 
bildung induziert. Gelingt dieses und kommt die vergrößerte Zelle dann zur Teilung, so ist ein verbreiterter vegetativer Klon etabliert. Das Austreten kann im Prinzip durch verschiedene Eingriffe erzielt werden, wie oben gezeigt durch $\mathrm{SiO}_{2}$ - oder $\mathrm{Mn}$ Mangel oder durch Kultur ohne EDTA; bei sehr schmalen Zellen - die Neigung zum Plasmaaustritt steigt mit sinkender Zellgröße-geschieht es sogar nicht selten "spontan“, insbesondere nach Überimpfen und Erhöhung der Lichtintensität. Praktisch und routinemäßig verwenden wir das erste Mittel, wenn sehr breite Stämme gewünscht werwerden. Die Alge wird bei $700 \mathrm{Lux} / 15^{\circ} \mathrm{C}$ in Nährlösung ohne die Kieselsäuregabe kultiviert, bis infolge $\mathrm{SiO}_{2}$-Mangels Plasmaaustritte erfolgen, dann wird in eine größere Kulturschale umgefüllt und mit normalem $\mathrm{SiO}_{2}$-haltigem Medium verdünnt, worauf die Regeneration erfolgt. Spontane Vergrößerung kann benützt werden, wenn man geringere Zellbreiten nötig hat.

Die Schalen werden nach einer Woche auf vergrößerte Kolonien hin durchgesehen und diese in den gewünschten Breiten isoliert und weitergezogen. Von den ausgetretenen Protoplasten ist jeweils nur ein geringer Teil imstande, die Regeneration durchzuführen, der Rest stirbt ab. Die Vergrößerung läuft nicht nach einem immer gleichen und geregelten Muster $a b$ wie bei der Auxosporenbildung und führt daher zu Regeneraten mit anormalen Zellquerschnitten. Diese regulieren sich bei Stephanopyxis mit seinen zarten Schalen aber im Verlauf der nächsten Teilungen auf die normale Kreisform ein. Wirksam sind dabei vermutlich Oberflächenspannungskräfte. Setzt man breite Zellen der gleichen Behandlung ( $\left.\mathrm{SiO}_{2}-\mathrm{Mangel}\right)$ aus, so erhält man aus sanduhrförmig eingeschnürten Protoplasten gelegentlich auch verschmälerte Klone.

Wie wir sehen werden, hängen die morphologischen und entwicklungsphysiologischen - tatşächlich auch alle übrigen physiologischen - Eigenschaften der Diatomeen-

zelle von der Zellbreite ab. Anders als bei den übrigen Organismen ist hier also nicht nur das "genetische Make-up", sondern eine weitere innere Bedingung (der Ort im überindividuellen Größenzyklus) bestimmend für die Reaktionsnorm. Die experimentelle Beherrschung der Zellgröße ohne Genomänderung wird daher genaugenommen eine conditio sine qua non für ein längeres Arbeiten mit allen denjenigen Formen, welche dem Größenwechsel unterworfen sind.

\section{Die morphologische Untersuchung}

\section{Die Technik der Lebendbeobachtungen}

Obwohl Stephanopyxis mit etwa $100 \mu$ maximaler Zellbreite in der bei marinen Planktondiatomeen realisierten Skala nur zu den Arten mittlerer Größe gehört (Coscinodiscus concinuus, die größte Diatomee unserer Gewässer, erreicht $450 \mu$ ), ist eine Beobachtung der wichtigsten Lebensvorgänge bereits mit der 40 fachen binokularen Lupe in der Kulturschale möglich. Selbst die Spermien können dabei erkannt werden, wenn man durch Herausnehmen des Hohlspiegels aus der optischen Achse eine (einseitige) Dunkelfeldbeleuchtung herstellt, wozu als Lichtquelle eine mattierte 60-W-Glühbirne genügt - eine übrigens auch für Isolation kleiner Flagellaten und ähnliche Arbeiten sehr nützliche Anordnung. 
Will man mehr sehen, so werden Objektive höherer Apertur und besseren Korrektionszustandes notwendig. Um letztere voll ausnützen zu können, sind drei Bedingungen einzuhalten: 1. Der nötige Arbeitsabstand Objekt zu Frontlinse beziehungsweise zu deren Fassung ist zu schaffen. Man verwendet zweckmäßig Objektive, bei denen dieser Abstand nicht zu gering ist. 2. Die den Korrektionszustand der Objektive beeinflussenden Faktoren sind optimal zu halten. Es ist also darauf $\mathrm{zu}$ achten, ob ein Objektiv mit oder ohne Deckglas korrigiert ist. Bei den für unsere $Z$ wecke geeigneten Trockensystemen ist das erstere der Fall, und das Deckglas muß bei Aperturen über 0,40 bis 0,50 yerwendet werden. Wasserimmersionen bis n. A. 0,65 können zur Not mit oder ohne Deckglas benutzt werden; solche höherer Apertur nur entsprechend der Vorschrift des Herstellers entweder mit Deckglas oder ohne Deckglas. Olimmersionen kommen für Lebendbeobachtungen hoher Auflösung weniger in. Frage. 3. Eine für Lebendbeobachtungen ausreichende Beleuchtungsapertur von etwa 0,7 liefert zum Beispiel der 3-linsige Kondensor n. A. 1,40 von Leitz nach Entfernen der Frontlinse, der den Vorzug hinreichenden Arbeitsabstandes besitzt. Phasenkontrasteinrichtungen eignen sich für feinere Beobachtungen an Diatomeen nur in seltenen Fällen.

Um mit starken Systemen trotz ihres meist geringen Arbeitsabstandes die Untersuchung des lebenden Objektes durchführen zu können, wurden zahlreiche Beobachtungskammern konstruiert (s. allgemein ReUMUTH \& LOSKE 1962, für unseren $Z$ wweck Rieth \& v. STOSCH 1954, v. Stosci 1954b), die aber in ihrer Benutzung unhandlich sind und immer die Gefahr bringen, die recht empfindlichen Objekte durch kaum vermeidbare Unsauberkeiten zu schädigen. Wir sind daher in den letzten Jahren mehr und mehr dazu übergegangen, die Beobachtung mit Tauchsystemen in der Kulturschale selbst durchzuführen. Die Schale wird dabei auf eine in den Objektführer des Mikroskops eingespannte Glasplatte aufgesetzt und eventuell mit dieser durch eine Glycerin"Immersion" (Ausgleichung der optischen Wirkungen von Unebenheiten des Schalenbodens) verbunden. Nach oben wird die Schale durch eine für den Durchtritt des Objektivs gelochte Glasplatte oder eine entsprechend behandelte Polyäthylenfolie abgedeckt. Unter diesen Umständen sind Dauerbeobachtungen von 24 Stunden und mehr zu erreichen.

Trockensysteme und deckglasbedürftige Wasserimmersionen werden dazu mit einer unten mit einem durch Paraffin aufgekitteten Deckglas verschlossenen Tauchkappe aus Polyvinylchlorid (PVC) oder Plexiglas (Abb. 1) versehen. Dabei ist zu

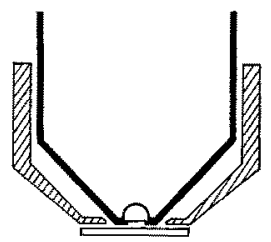

Abb. 1: Taudhkappe für Trockensysteme und mit Deckglas korrigierte Wasserimmersionen

beachten, daß Trodkensysteme und Wasserimmersionen auf Deckgläser von $0,17 \mathrm{~mm}$ (England und USA $0,18 \mathrm{~mm}$ ) Dicke korrigiert sind. Auf den Luftzwischenraum sollte bei ersteren das Deckglas und auf dieses sogleich das Objekt folgen. Dickere Wasser- 
schichten bewirken (wie dickere Deckgläser) eine Überkorrektion, welche bei Objektiven mit höherer Apertur als $0,40 \mathrm{zu}$ merklichen, über 0,65 zu starken Verschlechterungen der Bildqualität (Schärfe, Kontrast) führt (z. B. Mrchel 1950, Sprnell \& LoveLAND 1960). Man wird daher den Luftspalt so groß machen, wie mit dem Arbeitsabstand verträglich. Will man den letzteren erhöhen, so kann man dünnere Deckgläser verwenden; das dann unterkorrigierte System wird durch etwas dickere Wasserschichten auf den richtigen Korrektionszustand gebracht. Wasserimmersionen mit höherer Apertur als 0,65 der üblichen Ausführung verlangen Deckgläser; die relativen Längen der objektiv- und der objektseitigen Strahlenwege im Wasser spielen keine Rolle. Man wird also die Wasserschicht zwischen Frontlinse und Deckglas möglichst gering machen, um objektseitig genügenden Arbeitsabstand zu erhalten. Mit starken Wasserimmersionen (z. B. WI 90, Ap. 1,20 von Leitz) wird man auf diesem Wege nur bei Verwendung von Kulturschalen mit optisch planem Boden arbeiten können. Die Objektive sollen zur Verwendung mit Tauchkappen möglichst schmal sein, solche mit „eingebautem Deckglasschutz" sind ungeeignet. Man versuche, vom Hersteller Objektive ohne diese (für Ungeübte gedachte) Einrichtung zu bekommen. Die $22 \times$ Wasserimmersion ( $\mathrm{Ol}+\mathrm{W}, 22: 1$, n.A. 0,65) von Leitz dagegen kann direkt eingetaucht werden, wird aber zum Schutz von Objektiv und Objekt am besten paraffiniert ${ }^{5}$. Neuerdingst stellt die Firma E. Leitz, Wetzlar ${ }^{6}$, auf unsere Bitte eine achromatische 50 fache Wasserimmension (n.A. 1,00) her, die, ohne Deckglas korrigiert, mit hohem Arbeitsabstand sowie seewasserfest ausgeführt ist und die für unsere Arbeiten zweckmäßige, schmale Form besitzt. Mit dieser Immersion wurde ein Teil der Photos dieser Arbeit hergestellt. Sie kann direkt eingetaucht werden. Die wiedergegebenen Aufnahmen wurden mit Hilfe handelsüblicher oder in unserem Institut konstruierter Mikroblitzgeräte gewonnen.

\section{Zur zytologischen Technik}

Stephanopyxis ist karyologisch unter den Diatomeen kein besonders günstiges Objekt, wenn es auch sehr viel mehr zeigt als etwa Melosira varians (v. Srosch 1951). Wir werden deshalb die Kernvorgänge nur kursorisch behandeln und auch nur eine Standard-Technik für die zytologische Untersuchung angeben.

Nach Filtrieren der Kultur durch ein Drahtsieb ${ }^{7}$ oder eine Nutsche (Schott 12 G 3) - auf denen die Zellen dabei wie auch bei den folgenden Schritten nicht trockenfallen dürfen - erfolgt die Fixierung durch rasches Auf- und Durchgießen der Fixierungsflïssigkeit. Darauf wird im ersten Falle in die Nutsche umgegossen, in der die weitere

5 Paraffinieren einer Wasserimmersion: Man bringt die Immersion, Frontlinse nach oben, auf den Tisch einer 6-10 $\times$ Lupe, beleuchtet von unten und stellt auf die Frontlinsenoberfläche scharf ein. Es erscheint in dieser Oberfläche ein heller, scharf begrenzter Lichtfleck. Bis an diesen heran darf das Paraffin aufgetragen werden, das dann also über den Rand der Fassung hinweg auf die Linsenoberfläche reicht. Geeignet ist eines der zäheren Einbettungsparaffine ( $z$. B. Gummi-Wachs-Paraffin); zum Auftragen dient ein auf entsprechend niedrige Leistung gestellter Kleinlötkolben mit spitzem Einsatz.

6 Wir sind der Firma Leitz, insbesondere Herrn D.. H. Claussen, der auf unseren Wunsch einging und die Konstruktion durchführte, in größtem Dank verbunden.

7 V2A Stahl-Drahtnetz von $45 \mu$ Maschenweite wird auf einer $320^{\circ} \mathrm{C}$ warmen Metallplatte an ein an den Enden plangedrehtes Plexiglasrohr von etwa $14 \mathrm{~mm}$ lidter Weite und $60 \mathrm{~mm}$ Länge aufgeschweißt. 
Behandlung erfolgt (Nutsche bei längeren Behandlungen an beiden Enden verschließen). Als Fixiergemisch dient Methanol-Ameisensäure (3:1); im Gegensatz zu Alkohol-Eisessig verursacht es nur geringfügiges Kollabieren der Zellen. Zur besseren Erhaltung der Spindel kann nach einigen Stunden in einem formolhaltigen Gemisch $(50 \%$ Methanol $100 \mathrm{ml}$, Essigsäure 2,5 ml, Formol $6 \mathrm{ml}$ ) nachfixiert werden. Nach 24 Stunden erfolgen Überführung in Essigsäure (50\%) mit 2 bis 3 Zwischenstufen, Färben in Eisenkarminessigsäure kalt (30 Min.), dann bei $80^{\circ} \mathrm{C}$ (15 Min.) Überführung in Phenol-Essigsäure 50\% (1:3, dann 2:2 und 3:1 in sehr rascher Folge) und zuletzt in Phenol. Schließlich wird das Deckglas aufgelegt und mit Phenol-Caedax umrandet (v. STOSCH 1952).

\section{MORPHOLOGIE UND VEGETATIVE TEILUNG VON ZELLE UND KOLONIE}

\section{Bau der Zelle}

Die ruhenden Zellen von Stephanopyxis sind paarweise durch die ineinandersteckenden zylindermantelförmigen Gürtel (Pleuren) ihrer Oberschalen vereinigt, sowie außerdem durch Borstenkränze auf jeder Valva, die auch die Paare untereinander
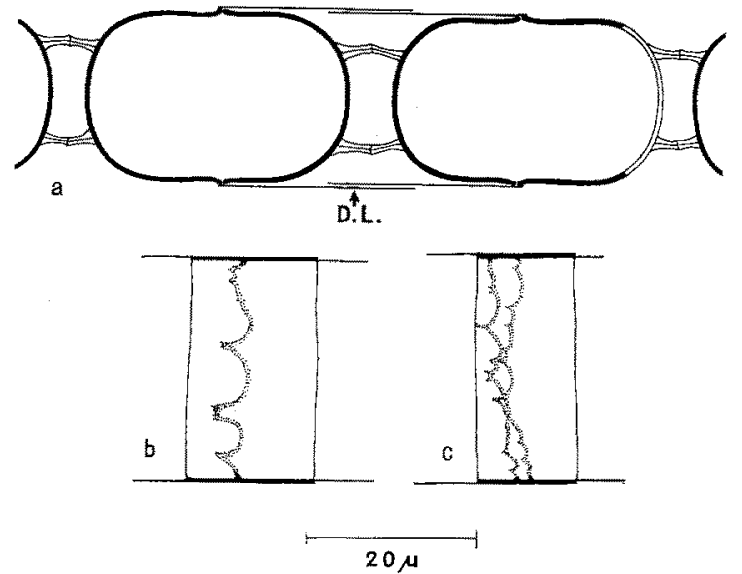

Abb. 2: a Schalen eines Paares ruhender Zellen von Stephanopyxis im Längsschnitt (schematisch). Valven mit den Rändern aufeinandergepreßt; nur die Epivalven tragen daher Gürtel, welche mittels der Gürtelfalz an den Valven befestigt sind. Der Gürtel der Paarepitheca ubergreif den Gürtel der Paarhypotheca in der Gütelfuge, deren Begrenzungen sich auf der Gürteloberfläche als zwei zarte Linien markieren. Eine dritte Linie (D. L.) wird durdh innerhalb der Gürtelfuge der Paarepivalva angelagertes Material erzeugt. Ganz rechts ist derjenige Teil der Valva, welcher als $D$ is $k$ us bezeichnet wird, ungefüllt vom gefüllt dargestellten $\mathrm{M}$ an te $\mathrm{l}$ abgesetzt. $b$ einfache, $c$ doppelte "Dritte Linie in Aufsicht auf den Gütel; nach gefärbtem Material

zu Linearkolonien verbinden (Abb. 2). Während also die Epivalva jeder Zelle an ihrem Rande eine Pleura trägt, ist dieses bei der Hypovalva nicht der Fall; diese ist mit ihrer Mündung derjenigen ihrer Epivalva direkt angepreßt und steckt damit inner- 
halb des Gürtels der letzteren. Die Gürtel selbst haben etwa die $11 / 2$ fache Länge einer Valve und übergreifen sich auf nicht ganz $1 / 2$ dieser Strecke. Da die Gürtel recht dünnwandig sind, wird ihre Doppelnatur im optischen Schnitt nur in einer Verdickung des Gürtelzylinders und in der Aufsicht durch die beiden sehr zarten Begrenzungslinien der Gürtelmündungen sichtbar (Abb. 2). Außer diesen beiden durch die Gürtelränder erzeugten Linien kann noch eine dritte sichtbar werden, deren $\mathrm{Zu}$ standekommen auf S. 227 besprochen ist. Dieser Diatomeentypus, der vor dem Strekkungswachstum der Zelle, bei dem sich der innere Gürtel ausbilden würde, in die interphasische Ruhe eintritt, ist nur bei zentrischen Diatomeen und dort nur bei den Melosirinae, also bei den Gattungen Melosira, Podosira-Hyalodiscus, Endictya, Pyxidicula, Stephanopyxis und Sceletonema vertreten. Alle übrigen Diatomeen haben in diesem Zustand zwei vollständige Schalen, da das Streckungswachstum bei ihnen im Anschluß an die Telophase stattfindet, allerdings manchmal sehr lange anhalten kann.

Die Form der Valven und damit der Zelle variiert innerhalb des Größenbereiches der Art stark. Bei maximal breiten Zellen ist sie diejenige eines Halbkugelmantels oder der Kalotte eines solchen (Abb. 3), bei schmalen die eines Zylindermantels, des „Schalenmantels" (valve jacket) mit aufgesetztem halbkugeligen Boden, dem „Discus". Ein

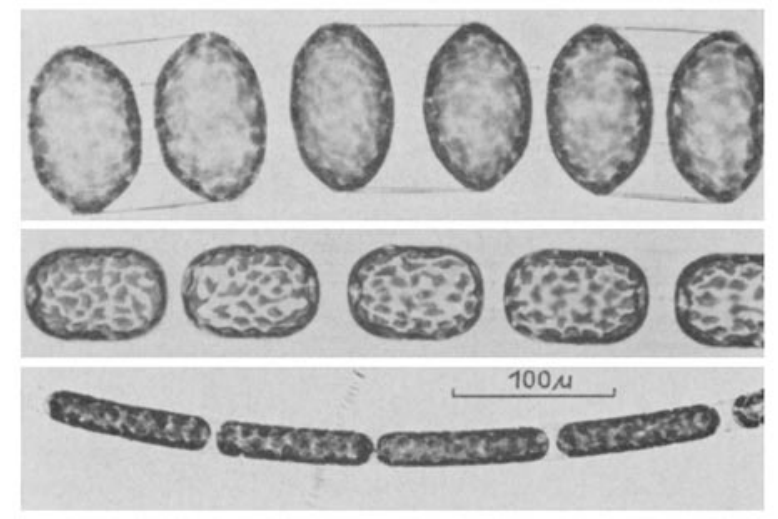

Abb. 3: Breite, kürzlich aus Auxosporen hervorgegangene, mittlere und schmale Ruhezellen von Stephanopyxis. Beachte Längenunterschiede

ganz kurzer Mantel fehlt übrigens auch den breitesten Zellen nicht. Die Zelle wird also mit sinkender Größe schlanker. Wie Abbildung 3 erkennen läßt, geschicht dieses nicht nur durch Breitenverringerung, sondern auch durch eine gleichlaufende, absolute Verlängerung der Valven, welche etwa linear mit abnehmender Breite länger werden. Dadurch wird der Volumenverlust, zu einem allerdings geringen Teil, kompensiert.

Die Valva trägt lichtoptisch ein Netz hexagonaler Maschen, das sich elektronenmikroskopisch auflöst (REIMANN 1960) zu einem System sehr flacher, 6eckig-prismatischer Kammern mit feinporiger Grundmembran und einem großen Kreisporus in der äußeren, oberen Abschlußmembran; ein Kranz etwa parallel der Zell-Längsachse gerichteter Stacheln ist ihr aufgesetzt und stellt die Verbindung mit den gleichen Bildungen der Nachbarzelle her, die sie Stachel für Stachel triff. Die Verkittung der 
beiderseitigen Fortsätze geschieht durch Gallertsubstanz und wird im Zuge der Kolonieteilungen wieder gelöst. Die Stacheln entsprechen je einer stark verlängerten und verengten Kammer mit durchbrochener Grundmembran. Sie sind durch die heraufgezogenen Wände der Nachbarkammern geflügelt und durch das kanalartige Kammerlumen durchbohrt. Im Gegensatz zur einstückigen Valva setzt sich der Gürtel aus etwa 20 ringförmigen, lichtoptisch nicht strukturierten und zur Gürtelmündung schmäler werdenden Bändern zusammen, die ihrerseits je aus etwa 6 von Band $\mathrm{zu}$ Band alternierenden Stücken bestehen ${ }^{8}$. Den einzelnen Ringsegmenten beiderseitig angeschnittene Laschen greifen in die Fugen zwischen den Segmenten der benachbarten Ringe (Abb. 4). Die Kieselstrukturen von Valva und Gürtel sind plattiert auf eine organische Membran, welche aus einem pektinartigen, saueren Kohlehydrat besteht. Nach neueren Untersuchungen (REIMANN, in litteris) werden die Kieselstrukturen auf der Außenseite

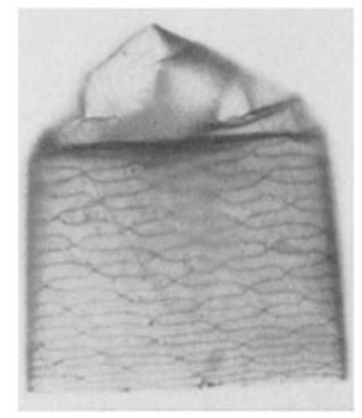

Abb. 4: Pleura von Stephanopyxis. Durch Auftrocknen auf Objektträger abgeflacht und mit Kristallviolett gefärbt. Die Gürtelbänder nehmen von der Gürtelfalz zum Gürtelrand hin an Breite ab. Jedes Band ist aus mehreren Einzelstücken zusammengesetzt

von einer zweiten sehr dünnen organischen Membran umhüllt. Da die Struktur der Gürtel wegen der Zartheit ihrer Kieselelemente direkt schwer zu sehen ist, wurde die Photographie (Abb. 4) nach Anfärben der saueren Kohlehydrate mit einem basischen Farbstoff (Kristallviolett) gewonnen. Sie gibt also nur den Abdruck der Kieselspangen in der organischen Substanz wieder. Elektronenoptisch erweisen sich die Gürtelbandsegmente übrigens als von zahlreichen feinen Poren durchbrochen, jedenfalls bei S. orbicularis (CASSIE \& BerTRAud 1960).

Ausgekleidet wird die Zelle von einem Plasmabelag geringer Mächtigkeit, der zahlreiche, etwas gelappte und mit je einem direkt schwer erkennbaren Pyrenoid (Abb. 8f, g) versehenen Plastiden enthält (Sichtbarmachung der Pyrenoide durch Blaufilter, z. B. Schott B.G. $12,2 \mathrm{~mm}$ ) und den großen einheitlichen Zellsaftraum umhüllt. In diesem Belag liegt im Scheitel der Hypovalva der Kern. Dieser zeigt bereits

${ }^{8}$ Man unterscheidet gewöhnlich an einer Theka das Gürtelband und, falls vorhanden, die zwischen dieses und die Valva eingeschobenen $Z$ wischenbänder. Da nun bei Rhabdonema mehrere untereinander gleichartige Bänder an der Thekenmündung durch von diesen strukturell scharf abgesetzte Zwischenbänder gefolgt sind, könnte man hier nur von mehreren Gürtelbändern sprechen. Damit bleibt die Terminologie nur dann logisch und allgemein verwendbar, wenn man bei klaren Unterschieden in Bau und Morphologie beide Bändertypen unterscheidet. Monoton e Gürtel wie bei Stephanopyxis besäßen also nu r Gürtelbänder. 
im Leben eine gleichmäßige, relativ grobe Körnung, die Querschnitte der durcheinander gewundenen Interphasechromosomen sowie einen bis vier Nukleolen sehr unterschiedlicher Größe (s. a. Abb. 9a). Heterochromatin tritt in Karminessigsäure kaum hervor.

Messungen über die Plastidenzahl liegen nur für zwei Zellgrößen vor. Die Plastiden wurden über $1 / 4$ der Zelloberfläche auf Photographien ausgezählt und die Werte dann für die ganze Zelle umgerechnet. Für eine Zellbreite von $57 \mu$ ergaben sich 243,3 \pm 8 ,8, für eine solche von $32 \mu 138 \pm 25,6$ Chloroplasten. Es handelt sich um die vor der Teilung verdoppelten Zahlen. Die Plastidenzahl scheint also proportional der Oberfläche abzunehmen (Erwartung auf dieser Grundlage für den zweiten Wert: 136,5). Bei Cocconeis (Pennales), die nur einen Plastiden besitzt, nimmt dieser in der Größe ab (GeItler 1932), ebenso der Kern, der bei Stephanopyxis nicht gemessen wurde; auffällige Größenänderungen fehlen bei diesem jedoch; BRUCKMAYER (1954) fand überraschenderweise eine Zunahme der Kerngröße mit sinkender Zellbreite bei Melosira nummuloides.

\section{Reaktionen der Stephanopyxis-Zelle auf Schock und Verdunkelung}

Für denjenigen, welcher mit Stepbanopyxis umgeht, ist es wichtig, einige häufige Reaktionen der Zelle auf Schädigungen zu kennen. Bei leichten Verletzungen, auch bei Hypotonie, treten Reizplasmolysen geringerer Art ein, die häufig mehrfache, lokalisierte und konvexe Einbuchtungen des Plasmaschlauches erbringen. Dauerdunkel und verschiedene Schädigungen, auch die Weiterentwicklung der erstgenannten Plasmosyseform, können zu "allmählichen Plasmolysen" führen, bei denen sich der Protoplast allseitig von der Wand ablöst und dann als Kugel oder Oval innerhalb der Schale liegt; beide sind reversibel wie auch die dritte von HöFLER (1963) als Kollaps bezeichnete Reaktion, welche von BüNnING (1935) zuerst bei vergleichbaren Objekten beschrieben wurde und sich durch gröbere mechanische Einwirkungen erzielen läßt. Der Plasmawandbelag bekommt am Reizort ein Loch und zieht sich dort beginnend innerhalb weniger Sekunden wie ein zurückweichender Vorhang von der ganzen Oberfläche zurïck, bis er als ein formloses Klümpchen an einer Stelle der Membran klebt. Der Vakuolensaft diffundiert danach aus, was sich bei leucosinreichen Zellen (S. 213) am Verlust der Lichtbrechung direkt nachweisen läßt. Bei Stephanopyxis ist der Kollaps mit großer Regelmäßigkeit reversibel, häufig selbst dann, wenn die Schale beschädigt wurde. Die Vakuole wird dann im Protoplasten neu gebildet (vgl. auch Bünning l. c.) und dehnt den letzteren nun im Verlauf von etwa 4 bis 5 Stunden wieder auf die alte Größe aus, worauf die Zelle - gegenüber den Nachbarn verspätet - zur Teilung schreitet. Waren zwei Protoplasten entstanden, so wird auch der kernlose von ihnen wieder turgeszent, und beide verschmelzen später zu einem einzigen. Die Reaktion dürte auch in der Natur stattfinden und ist vielleicht die Methode, Zeiten stärkster Turbulenzen zu überstehen. Sie tritt auch bei anderen Planktondiatomeen, etwa bei Biddulphia sinensis (BüNnING 1935) und Biddulpbia regia, ein.

Schließlich gibt es auf starke Schädigungen, zum Beispiel osmotischer Art, an gesunden Zellen und besonders in alten, lichtarm gezogenen Kulturen eine Erschei- 
nung, welche als „Blitztod“ bezeichnet sei. Blitztod kann bei „alten“ Zellen bereits auf leichte Erschütterungen der Kulturschale hin eintreten und wird durch augenblickliche Braunfärbung der Vakuolenflüssigkeit erkennbar. Offenbar geht ein Teil der Plastidenfarbstoffe (Phäophytin?) im Zellsaft in Lösung. Eine Protoplasmakontraktion findet nicht statt.

Dauerdunkelheit wird auch bei im Schwachlicht (300 R-Lux) angezogenen Zellen, welche gleich nach der Zellteilung isoliert und dem Licht entzogen wurden, also wohl frei von Reservestoffen waren, bemerkenswert lange ertragen. Der Protoplast löst sich dann erst von der Unterschale in allmählicher Plasmolyse ab und kontrahiert sich schließlich bis zur Kugelform. Diese Plasmolysen waren noch nach 21 Tagen reversibel $\left(15^{\circ} \mathrm{C}\right)$; die Deplasmolyse war nach Rückführung auf 2000 Lux nach etwa 24 Stunden beendet, die nächste Teilung setzte weitere 20 Stunden später ein.

\section{Die Zellteilung und die Bildung der neuen Schalen; die "Dritte Linie“}

Die Zweiteilung der Zelle von Stephanopyxis kommt vor a) als gewöhnliche, vegetative Teilung, b) in mehreren Formen spezialisierter Mitosen bestimmter entwicklungsmechanischer Dignität, bei der Dauersporenbildung sowie in den Differenzierungsteilungen der Spermatogonien. Nur von Fall a) ist hier zunächst die Rede.

Der Ruhezustand der Zelle wird bei Mangel an Licht sowie den Nährstoffen Stickstoff, Phosphor und Eisen beliebig lange beibehalten. In einem in Vermehrung befindlichen Material (Generationsdauer 24 Stunden) dauert der Ruhezustand etwa 171/2 Stunden (70\%). Doch erfolgt etwa in der Mitte der Ruhezeit, gegen Ende der Dunkelperiode, die Teilung der Plastiden, was zuerst Rermann (persönl. Mitt.) durch Zeitrafferaufnahmen nachwies. Etwa 6 Stunden danach beginnen sich die Tochterzellen der vorhergegangenen Teilung in Einleitung der mitotischen Prophase zu strecken und dadurch die sich übergreifenden Gürtel der Mutterzelle voneinander zu schieben (zum Folgenden siehe Abb. 5).

Wenn die Zone zwischen den Valvenrändern etwas weniger als $1 / 3$ ihres endgültigen Wertes (Gürtellänge der Ruhezelle) erreicht hat, beginnt das Streckungs w a ch stu m mit der am Rand der Hypovalva ansetzenden Ausscheidung der Hypopleura. Diese wächst mit fortschreitender Verlängerung der Zelle an ihrem freien Rand zu, bis der innere Gürtel die Länge des ihn übergreifenden Gürtels erreicht hat. Zwischen dem Rand der Hypopleura und der Epivalva bleibt also ein Anteil von $1 / 3$ (zuletzt etwas mehr) der endgültigen Pleuralänge einfach ${ }^{9}$. Die prophasische Streckung, die es auch bei anderen Diatomeen gibt, holt hier also das bei jenen in der Posttelophase absolvierte Streckungswachstum nach. Bei etwa $2 / 5$-Streckung wandert der Kern aus seiner Ruhelage im Scheitel der Hypovalva in den Zelläquator. Die Stredkung geht mit sich vermindernder Geschwindigkeit weiter, bis die Zelle die Länge des ursprünglichen Zellpaares besitzt. Die verringerte Wachstumsgeschwindigkeit drückt sich in dem in Abbildung 4 erkennbaren Schmälerwerden der Gürtelbänder aus.

9 Technik: Jod-Seewasser fixiertes Material wurde in Kaliumjodid-Quecksilberjodid (konz. wäßrig) untersucht (Phasenkontrast), einer Flüssigkeit von hohem Brechungsindex, welche gleichzeitige Beobachtung des Schalenbaues und des plasmatischen Inhaltes zuläßt. 
Der Kern, auf einem Plasmapolster ruhend, liegt nun als ein im optischen Schnitt halbkugeliger Hügel im Wandbelag des Zelläquators. Im fixierten Präparat wird der Übergang des Chromatins in den Prophasezustand erst spät, nämlich gleichzeitig mit oder nach einer Aufteilung der Nukleolen, sichtbar. Letztere schwinden danach, während die Flanken des Kernhügels - wohl wegen der Auflösung der Kernmembran und der Ausbildung der Metaphaseplatte - steiler (Abb. 8a), sein Gipfel schmäler wird. Das den Kern umhüllende Plasma neigt in dieser Zeit und noch in der Anaphase $(\mathrm{Abb} .8 b, c)$ zur Ausbildung amöboider Protuberanzen in den Vakuolenraum.

Die nun folgende Abflachung der Kernkontur an ihrem Gipfel entwickelt sich durch Streckung der Spindel alsbald zu einer die Tochterplatten trennenden Senke (Abb. 8b). Mit deren Verbreiterung wird auch die Spindel selbst als dicker hyaliner Strang sichtbar, der sich - mindestens häufig - wie dies Abbildung $8 c, d$ zeigt, von dem sich ebenfalls auseinanderziehenden und nunmehr hantelförmig einschnürenden Plasmapolster löst, so daß zwischen diesem und jener ein schmales Fenster sichtbar wird. Die Spindel liegt dann also in ihrem mittleren Teil dem Anschein nach frei im Zellsaft. Die Aufsicht auf die Teilungsfigur (Abb. 8g, b) bestätigt diesen Sachverhalt und zeigt außerdem, daß die Spindel (meist) in beträchtlichem Winkel zur Längsachse der Zelle steht. Die Diatomeen besitzen eine recht schlanke Zentralspindel, welcher die Chromosomen vermittels ihrer Centromeren nur von außen ansitzen (Abb. 9d,e). Die Spindel verlängert sich nun beträchtlich und drückt die Tochterplatten auseinander, wobei auch die Durchschnürung des Tragpolsters der Kerne vollzogen wird (Abb. 8, b-i).

Ein derartiger „Stemmkörper" wurde zuerst von BELAR (1929) bei Heuschreckenspermatocyten nachgewiesen. $\mathrm{Daß}$ er sich bei Diatomeen autonom verlängert, läßt sich in den Spermatogonienmitosen und in der Spermatozytenmeiose einiger BiddulpbiaArten und ihrer Verwandten deutlich erkennen, da er dort durch Zerreißen seiner Plasmahülle während der Anaphase völlig frei gelegt wird, in ähnlicher Weise, wie dies sehr spät in der Stephanopyxis-Zytokinese geschieht (siehe unten). Etwa 8 Minuten, nach Einsetzen der Anaphase - rund 5 Stunden nach jenem der Streckung - beginnt, bei fast maximal verlängerter Spindel die Zytokinese mit dem Erscheinen der Ringfurche am Protoplasten, welche zuerst auf der Seite des Kernes, gleich darauf auch gegenüber sichtbar wird. Der Turgor muß dann auf den Wert Null abgesunken sein. Die Furche ist fast vom Beginn in ihrer vollen Breite angelegt und vertieft sich nun rasch, so daß nach etwa 5 Minuten an ihrer engsten Stelle die Tonoplastenoberflächen verschmelzen, die Vakuolen damit durchschnürend; sie hat auch die Spindel mit nach. innen genommen - die Kerne liegen dann auf ihren Flanken (Abb. 8i, j), welche in diesem Augenblick einen rechten Winkel bilden - und legt beim weiteren Einschneiden die Spindel als dünnen Strang frei (Abb. 8k). Das darauf folgende Auseinanderweichen der freien Menisken (Abb. $5 e, f ; 8 k ; 11 j$ ) wird möglicherweise durch eine weitere aktive Verlängerung der Spindel bewirkt oder unterstützt. Schließlich b r i ch t dieser letzte „Plasmafaden", seit langem als solcher beschrieben (Bergon 1907, Peragallo 1907), aber in seiner wahren Natur nie reche erkannt, in zwei Halbspindeln auseinander, deren außenliegende Reste dann in wenigen Sekunden eingeschmolzen sind. Die Spindel ist in ihrem freien Teil zwischen den Plasmamenisken zuletzt leicht bogenförmig gekrümmt, ihre Basen an der Plasmaoberfläche zeigen in die Richtung der Kerne, in denen sie verankert ist. Sogleich nach dem Bruch schnellen die entstandenen, spitz zu- 


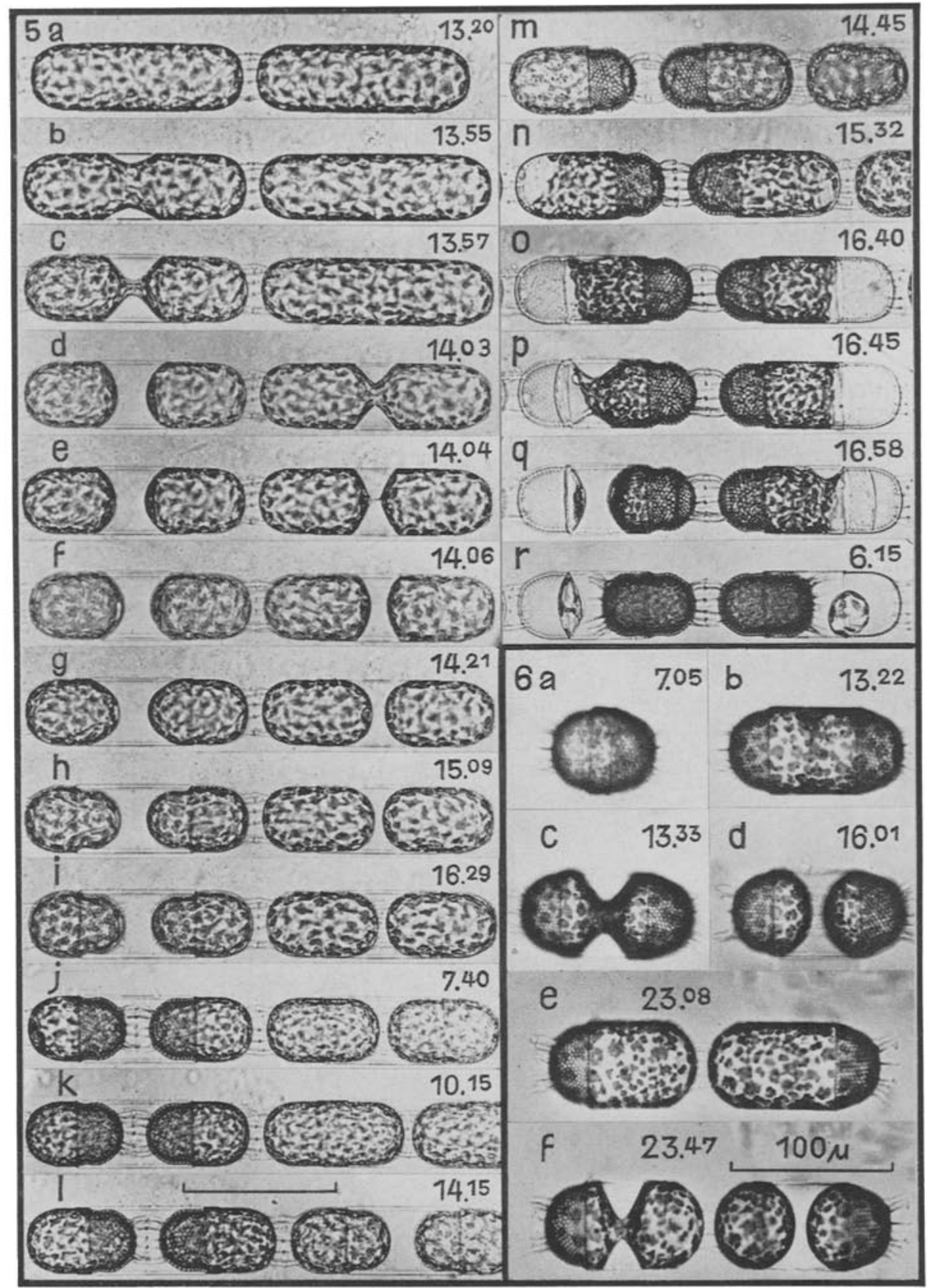

Abb. 5: Die linke Zelle entwickelt sich durch heterovalvate Teilung zum Dauersporenpaar, während die rechte Zelle sich vegetativ teilt; die linke Tochterzelle letzterer macht dann (zwischen $k$ und $l$ ) ebenfalls die heterovalvate Teilung durch; zwischen $i$ und $j$ Vermehrung der Plastiden. Uhrzeit angegeben. Weitere Erklärungen im Text. Maßstab: $100 \mu$ Abb. 6: Keimung einer Dauerspore. Uhrzeit angegeben 
laufenden Enden elastisch so empor, daß ihre Verlängerung etwa durch die Kernmitte geht, doch bleibt dieser Zustand nur für Sekunden sichtbar. Auch das Auseinanderbrechen der Halbspindeln und deren Elastizität gibt es bei den Biddulphia-Spermatogonien (weitere Einzelheiten siehe Legende Abb. 8).

Die zuletzt, wahrscheinlich im Zusammenhang mit der Spindeltätigkeit ziemlich flach gewordenen Menisken der freigelegten Plasmaoberflächen wölben sich im Verlauf der nächsten halben Stunde infolge einer leichten postzytokinetischen Schwellung des Protoplasten stärker auf (Abb. 5f- h). Die neue Oberfläche der Halbzelle ist damit auf die endgültige Form gebracht, die nunmehr durch Ausscheidung des Kieselmaterials der Hypovalva fixiert wird. Nach ReIMANn (1960) beginnt die Verkieselung in einer Zone nahe dem Discusrand und schreitet von hier einerseits auf den Mantel, andererseits zur Discusmitte hin fort. Die erste dünne Kieselmembran ist bereits 5 Minuten nach Beginn der Ausscheidung fertiggestellt. Nach weiteren 10 Minuten wird auch das Wabenmuster der Schalen erkennbar (RemanN). Im Zuge dieses Vorganges erscheinen sehr bald die Anlagen des Stachelkranzes, die in dem Raum zwischen den jungen Valven vorwachsen und sich dort paarweise vereinigen. Dabei schwellen sie nahe den Berührungsflächen etwas an. Nach REIMANN (1960), der die Schalenbildung synchronisiert mit lichtoptischen Beobachtungen der Zellteilung elektronenmikroskopisch verfolgte, bildet sich zunächst ein hexagonales Netz rundlicher Bälkchen, auf denen nach außen die Lamellen der Kammerwände auswachsen. Senkrecht zu diesen letzteren wird die der Plasmaoberfläche parallele und zunächst liegende Grundmembran als feinmaschiges, orthogonales Balkennetz ausgeschieden, dessen Maschen nun bis auf winzige kreisförmige Poren zuwachsen. Zuletzt entsteht parallel zur Grundmembran die Decklamelle der Kammern, welche jedoch, durch die große Kammeröffnung durchbrochen, nur einen schmalen Rand um diese herum bildet (Einzelheiten bei REImann 1960). Der Vorgang der Furchung bis zum Brechen der Spindel dauert etwa 7 Minuten; die junge Valva ist in weiteren $11 / 2$ bis 2 Stunden fertiggestellt.

Die Formbildung der jungen Schale bedarf der Erläuterung. Zunächst wird bereits aus den Abbildungen klar, daß die Furchung von einem beträchtlichen Flüssigkeitsverlust seitens der Vakuole begleitet ist. Während die vorhergehende Streckung zweifellos durch positiven. Turgor bewerkstelligt wird, sinkt dieser zur Furchung hin anscheinend auf Null ab. Dafür spricht, daß es in dieser Zeit auch abseits vom Zelläquator zu Ablösungen des Plasmas von der Wand kommen kann (Abb. 5p, q). Wie dieses "Welken" des Protoplasten geschieht, ist nicht untersucht. Man könnte denken an 1. ein Undichtwerden der Plasmagrenzschichten für den Vakuolensaft oder einzelne seiner Bestandteile, 2. eine aktive Ausscheidung von Wasser durch einen Transportmechanismus oder 3. eine Herabsetzung der osmotischen Aktivität der Vakuolenflüssigkeit durch kondensierende Synthesen.

Die Topologie des Verlaufs der Furchung, welche grob als gezielte Spontanplasmolyse beschrieben werden kann, ist mitbestimmend, hier sogar fast allein bestimmend für die spätere Schalengestalt. Die Furche steht in räumlicher Beziehung zur Mitosespindel - nämlich in deren Mitte -, deren. Einfluß auch an dem Vorauseilen der Einschnürung in ihrer Nähe abgelesen werden kann. Die Anlegung und Ausformung der Furche kann der Tätigkeit von Gradienten in den Oberflächenkräften des Protoplasten zugeschrieben werden, $\mathrm{d}$ a $\mathrm{n}$ a $\mathrm{ch}$ spielt möglicherweise die Streckung des "Stemm- 
körpers ihre Rolle beim Auseinanderbringen der jungen Menisken, worauf deren Abrundung wohl durch die Oberflächenspannung bei gleichzeitigem Ansteigen des Turgors bewirkt wird. Während aber in der Oberfläche angreifende Furchungskräfte durch die Form der Furche nahegelegt werden (letztere ist im Schnitt winklig und sollte, wenn durch eine Saugung negativen Turgors bewirkt, rund-konkav sein), läßt sich eine verformende Wirkung der Spindel nur im Analogieschluß (s. oben) plausibel machen. Grundsätzlich könnte bei genügender Wandhaftung des Plasmas beiderseits der Furchungsfläche die Formänderung der Menisken auch durch ein Auspumpen von Vakuolensaft als eine Einsaugung erklärt werden; die Vakuolenflüssigkeit müßte anderenfalls durch die immerhin recht dünne Spindel ausgepreßt werden. Beides mag jedoch auch zusammenwirken. Man könnte die Gesamtrorgänge um die Furchung als Gestaltungsbewegungen bezeichnen, wie solche in der Embryonalentwicklung der Tiere, jedoch auf der Basis eines vielzelligen Systems, eine Rolle spielen. Zuletzt wird die Form noch durch die Ausscheidung der Kieselschale durch die Plasmaoberfläche beeinflußt, die einerseits durch ihr Dickenwachstum den Protoplasten weiter nach innen schiebt, wie das besonders bei den dickwandigen Dauersporen (S. 231) deutlich wird, und andererseits durch das Aussprossen der Borsten die Außenkontur umgestaltet. Die Borsten sind hohl (Mülizer 1900) und von einem vorgebildeten Plasmafaden eigentümlicher Entstehung durchzogen.

Die Umrißform der Valven, insbesondere das Verhältnis zwischen Mantel und Diskus, wird hier also praktisch durch die Breite und die Form der Furche bestimmt (siehe aber Guinardia, weiter unten). Bei sehr breiten Zellen fehlt der Mantel fast ganz, offenbar weil die verfügbare Länge der Pleura nur für die Furche selbst ausreicht (siehe aber S. 237). Die Furche schneidet in diesem Falle spitz ein; die Menisken können im Zeitpunkt des Spindelbruches fast eben sein. Bei schmäleren Zellen bildet, wie oben geschildert, das Furchungsdiabolo einen rechten Winkel zwischen seinen kegeligen Teilen, und die nicht von dieser Figur benötigte Pleura-Oberfläche wird zum Mantel. Bei Zellen gleicher Breiten können die Schalenformen weiter durch den Beitrag der Strekkung modifiziert werden, so wirkt Schwachlichtkultur beispielsweise verkürzend, Temperaturerhöhung verlängernd. Uber die Abhängigkeit des Ausmaßes der Streckung von Außenbedingungen fehlen aber noch eingehende systematische Erfahrungen. Bei Stephanopyxis bleibt der Kern auch nach Beendigung der Schalenbildung in der Hypovalva liegen, die Melosiren (v. Sтоsсн 1951) aber lassen ihn danach in die Epivalva zurückkehren.

Wir hatten bereits auf S. 220 und mit Abbildung 2 (siehe auch Abb. 14b) auf das Vorhandensein einer "Dritten Linie" zwischen den durch die freien Enden der Gürtel markierten beiden Linien aufmerksam gemacht. Das Zustandekommen dieser "Dritten Linie“" die übrigens in mehr als einem Einzelband auftreten kann, muß deshalb diskutiert werden, weil diese Struktur dem Beobachter sehr viel mehr auffällt als die beiden vorher genannten Linien. Die "Dritte Linie" bildet innerhalb der Gürtelfuge (zum Terminus siehe Legende Abb. 2) eine scheinbare Verdickung, die sich beim Heben und Senken des Tubus zu einem Ring vervollständigt. Viel besser wird dieser letzte erkannt, wenn das Material nach Fixierung (z. B. Jod-Seewasser, dann $10 \%$ Formalin-Seewasser) und Auswaschen in Wasser mit Kristallviolett angefärbt wurde, wie in den Vorlagen zu Abbildung $2 b$ und $c$ geschehen. Er nimmt dann eine ziemlich 
intensive Färbung an. Beobachtungen an leicht gequetschten Zellpaaren, deren beide Pleuren sich in der Fuge voneinander abhoben, zeigen, daß die gefärbte Substanz innerhalb der Fuge, und zwar immer als Anlagerung auf der Innenseite der Paarepipleura ausgebildet ist. Im Gegensatz zu den mehr oder weniger glatten Begrenzungen der Gürtelränder zeigt die zwischen ihnen liegende „Dritte Linie“ unregelmäßigen und stark welligen Verlauf, iber dessen besondere Art noch zu sprechen sein wird und, falls mehr als eine solche Linie an einem Gürtel gefunden wird, so ist der Verlauf der Einzelbanden voneinander unabhängig, letztere können sich beispielsweise überschneiden (Abb. 2c). Da außerdem von den beiden Gürtelfugen eines zusammengehörigen Zellquadrupels die eine (in Beziehung auf den Quadrupel hypovalvare) immer nur eine einfache Linie trägt, während sie bei der anderen gewöhnlich in 2- oder 3-Zahl auftritt, wird wahrscheinlich, daß die "Dritte Linie" eine im Verlauf jeder Zellteilung in Einzahl, und zwar auf die Epipleura-Innenfläche gedruckte Marke darstellt, welche durch die Epivalva „vererbt" wird. Es besteht eine gewisse Analogie zu den „Kappen" von Oedogonium.

Der Zeitpunkt der Ablagerung der Marke könnte entweder kurz nach der Zytokinese, im Zusammenhang mit der eigentümlichen Ausbildung der Schalenborsten oder kurz vor oder während der Zytokinese gesucht werden. Da aber die Quadrupelhypovalva bereits kurz nach der Zellteilung (lange vor der Borstenbildung) die Marke besitzt, sie der Paarhypopleura im Zustande fortgeschrittener Streckung jedoch fehlt (einem Zeitpunkt, zu dem sie bei der entsprechenden Epipleura bereits existiert), wäre die erste Möglichkeit auszuschließen. Die Setzung der "Dritten Linie“ muß also während oder ganz kurz vor der Zytokinese geschehen. Betrachtet man nun die Form dieser Linie genauer, so fällt auf, daß ihr "unregelmäßig welliger" Verlauf aus Spitzen und sie verbindenden Bögen besteht; die Spitzen sind, auch wo mehrere „Dritte Linien“ vorhanden sind, immer nach der gleichen Seite, nämlich der Epitheka hin, die Bögen aber entgegengesetzt gewendet. Mit anderen Worten: die Spitzen zeigen auf den freien Rand der Hypopleura, dem die ganze Linie innerhalb der Gürtelfuge genähert liegt. Verformt man einen elastischen, dünnwandigen Hohlzylinder, wie ihn eine Hypopleura ja darstellt, indem man versucht, seinen freien Rand zur Achse hinzuiehen, so weicht dieser Rand in eine Anzahl flacher Falten aus, deren Begrenzungen gegen den nicht verformten Teil des Zylinders sich in einer dem Verlauf der dritten Linie ähnlichen Kontur vereinigen. Die Dritte Linie wird nach unserer Deutung infolge eines leichten Abhebens des Randes der Hypopleura von der Epipleura, und zwar durch Zug von innen her dadurch hergestellt, daß exosmierende organische Substanz in den geschaffenen Raum eindringt und sich in dessen keilförmigen Kanten sammelt. Wird die Spannung an der Hypovalva später aufgehoben, so geht diese in ihre alte Lage zurück und druckt dabei das angesammelte Material auf die Epipleura-Innenseite auf. Daß dieses letztere nur an der Epipleura-Innenseite und nicht auch an der HypopleuraAußenseite haftet, dürtte durch den Unterschied in Struktur und Chemismus beider Oberflächen (S. 221) bedingt sein. Einzelne Bänder der dritten Linie können, falls in Mehrzahl vorhanden, und nur dann, auch uber den Rand der Hypopleura hinausragen oder ganz außerhalb desselben verlaufen. Dieses ist zu erwarten, wenn man bedenkt, daß Ausmaß der Streckung und demzufolge die Länge der Gürtelfuge und Lage des Hypopleurarandes innerhalb der Epipleura von Teilung zu Teilung etwas wechseln: 
Eine solche transgredierende Linie wird also aus einer vorherigen Teilung mit geringerer Streckung (und damit rela t i v stärkerem Streckungswachstum) stammen.

Eine Ausscheidung organischer Substanz in den von Gürtel und Plasmafurche begrenzten Raum läßt sich durch Anfärbung mit Kristallviolett sicherstellen. Sie könnte also auch im Zeitpunkt der Gürtelabhebung erfolgen. Sucht man den Zeitpunkt näher einzuengen, so fehlen uns im Augenblick Argumente, ihn in die Furchung selbst zu verlegen. Hechtsche Fäden zwischen Furchenfläche und Gürtel, die einen Zug übertragen könnten, wurden nicht nachgewiesen. So ist es wahrscheinlicher, daß das Ereignis kurz vor der Furchung eintritt. Etwa in folgender Weise: Die Zelle müßte nicht, wie oben angenommen Turgor Null, sondern einen negativen Turgor besitzen. Dieser würde sich durch die Adhäsion des Plasmas auf die Wand übertragen und diese am locus minoris resistentiae, eben dem Rand der Hypopleura verformen. Der negative Turgor und seine Folge würde mit Einsetzen der Furchungsbewegung aufhören, welch letztere dann eine lokalisierte Aufhebung der Plasma-Wand-Adhäsion bedeuten würde.

Auf die Vielfalt der postmitotischen Formbildungsvorgänge bei Diatomeen kann hier nicht eingegangen werden, doch sei erwähnt, daß bei manchen Arten der Gattung Melosira, welche etwa rechteckige Gürtelansichten besitzen, die Furche ganz schmal einschneidet und merkliche Protoplasmakontraktionen fehlen (Conard 1929, v. STosch 1951), daß bei Guinardia (SchütT 1900, Bergon 1902) die Dinge bis zur Abrundung der Menisken wie bei Stephanopyxis verlaufen, die Plasmakuppen dann aber, sich gegenseitig abplattend, gegeneinanderrücken, die postzytokinetische Schwellung also verstärkt ist und auf diese Weise annähernd flache Valven entstehen. Bei Biddulphia vollzieht sich der Gesamtrorgang der Schalengestaltung noch verwickelter, wie das die Schilderungen von BergoN (1907) und Peragallo (1907) demonstrieren.

Die Schalenfeinstruktur ist eine spezifische Leistung der Plasmaoberfläche, ihr sollte als Korrelat ein Muster der letzteren entsprechen, und dieses weit in den submikroskopischen Bereich durchgestaltet sein, ein Postulat, das mit den existierenden Strukturhypothesen noch kaum zu vereinbaren ist.

\section{Kolonieteilung}

Die Kolonien der planktischen Diatomeen besitzen durch die Außenbedingungen beeinflußte Längen, welche durch den Mechanismus der Kolonieteilung hergestellt werden. Bei Arten mit durch Kieselsäureausscheidungen verwachsenen Schalen werden dazu vermittels heterovalvater Teilungen Paare von nicht verwachsenden und auch meist abweichend gestalteten "Trennschalen " eingeschaltet, wie dieses zuerst ScHütT (1888) für Chaetoceros beschrieb. Bei Stephanopyxis (wie bei anderen nur durch Verbindungsgallerte vereinigten Arten) scheint das gleiche durch das mit dem progressiven Altern gekoppelten Sichlockern der Gallertverbindungen zwischen den Borsten bewirkt zu sein, das die sich etwa intrasynchron teilenden Kolonien von, je nach Bedingungen 8, 16 oder 32 Zellen, jeweils nach Erreichen der verdoppelten Zellenzahl in zwei gleiche Hälften zerfallen läßt. 


\section{UBER DIE INNEREN UND AUSSEREN BEDINGUNGEN DER ENTWICKLUNG VON STEPHANOPYXIS}

Nicht nur Zellform (Abb. 3), Plastidenzahl oder -größe (S. 222), sondern auch die entwicklungsphysiologischen Potenzen hängen bei Diatomeen von der Zellbreite $\mathrm{ab}$, welche als eine innere Bedingung aufgefaßt werden kann. Uber den Gang der Generationsdauer mit der Zellbreite liegen keine näheren Untersuchungen vor, obwohl sie von großem Interesse wären. Fest steht nur, daß bei sehr schmalen Zellen nahe am unteren Rande des artspezifischen Breitenbereichs die maximale Teilungsfrequenz stark erniedrigt wird.

Die Bildung der Sexualorgane ist bei Diatomeen nach bisherigen Angaben (GEITLER 1932, v. STOSCH 1951, 1956) auf den unteren Teil des Breitenbereichs beschränkt, derart, daß bei den Centrales die Zellen aller Größen je nach der Art bis herauf zu $2 / 5$ bis $1 / 5$ maximaler Breite sexuell werden können, größere jedoch nicht. Bei Pennaten liegen die Dinge ähnlich, nur sind hier sehr schmale Zellen wieder nicht mehr zur Sexualisierung imstande. Ferner werden bei zentrischen Diatomeen die breiteren unter den sexualisierbaren Zellen ausschließlich weiblich, die kleinsten ausschließlich männlich, während dazwischen eine Größenlklasse liegt, deren Glieder sich zwittrig verhalten, die Geschlechtsbestimmung ist also größenbegrenzt. Da pennate Diatomeen im allgemeinen isogam sind, kann über sie in dieser Hinsicht nichts ausgesagt werden; doch scheint bei der monözischen und oogamen Rhabdonema arcuatum in ähnlicher Weise ein oberer weiblicher und ein diesen überlappender unterer männlicher Bereich zu existieren; der diözischen $R$. adriaticum fehlt jedoch die untere Begrenzung für die weiblichen Zellen.

Bei Stephanopyxis ist die für andere Centrales aufgestellte Regel nur in modifizierter Form (Abb.7) gültig. Hier scheinen sehr schmale Zellen, wie bei den Pennaten, steril zu sein; etwas größere können aber bereits zu Spermatogonangien oder Oogonien

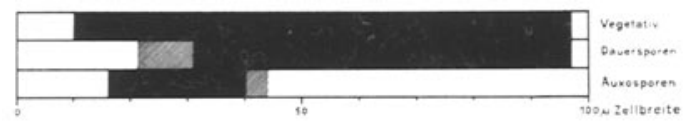

Abb. 7 : Fadenbreiten der Stephanopyxis, bei denen die Zelle vegetativ existenzfähig ist und Dauersporen oder Auxosporen bildet. Schraffiert: Bereiche erschwerter Differenzierung

werden, wenn auch erstere reichlicher als letztere auftreten. Umgekehrt werden auch an der oberen Grenze des sexuellen Bereichs zwar vorwiegend Weibchen, aber dazu auch Männchen beobachtet. Wenn also in der Größenskala Zellbreitenbereiche rein unisexueller Potenz existieren, sind sie so schmal, daß sie nicht gefaßt werden können. Man könnte versuchen, die Diskrepanz zwischen unseren älteren Angaben und dem Verhalten von Stephanopyxis darauf zurückzuführen, daß erstere sich auf Naturmaterial bezogen und daß am Standort genügend schmale Formen nicht mehr existenzfähig seien, während solche in Kultur noch zu halten sind. Jedoch können in Kulturen von Actinocyclus Ehrenbergii und Actinoptychus undulatus die wirklich äußerst schmalen Zellen minimaler Breite immer noch dazu gebracht werden, Männchen zu bilden, so daß derartige Unterschiede wohl auch artspezifisch sind. Welche Momente 
für den Unterschied von Typen mit unten "geschlossenen" (Stepbanopyxis) oder offenen sexuellen Bereichen maßgeblich sind, ist nicht bekannt.

Hinzu kommen bei Stephanopyxis noch die Dauersporen. Im Gegensatz zu den Sexualzellen können sie aus beliebig breiten Zellen entstehen bis herab in die Größenklassen, in denen bereits Sexualität möglich ist, wo ihre Bildungswahrscheinlichkeit aber immer geringer wird und zuletzt noch im sexuellen Bereich erlischt ${ }^{10}$ (Abb. 7 ). Ein ähnlicher relativer Antagonismus zwischen Sexualität und Dauersporenbildung besteht auch in den Außenbedingungen, besonders der Temperatur, über welche hier aber nur summarisch berichtet werden soll. Differenzierung vegetativer Zellen zu Dauersporen geschieht ganz bevorzugt bei tiefer Temperatur $\left(15^{\circ} \mathrm{C}\right.$ bis herunter auf $3^{\circ} \mathrm{C}$ ), während höhere Temperatur $\left(21^{\circ} \mathrm{C}\right)$ die Bildung von Sexualzellen fördert (die jedoch bis $15^{\circ} \mathrm{C}$ auch noch entstehen) und die Dauersporen zum Auskeimen bringt. Im übrigen differenziert die Alge von einem Material geeigneter Zellgröße aus, das bei $15^{\circ} \mathrm{C}$ und Schwachlicht von 300 Lux angezogen wurde und dabei kaum Dauersporen und keine Sexualzellen bildete, Dauersporen bei $15^{\circ} \mathrm{C}$ und 750 bis 2000 Lux, Sexualorgane aber massenhaft, wenn sie in frische Nährlösung und in Starklicht $\left(5000\right.$ Lux, $\left.21^{\circ} \mathrm{C}\right)$ überführt wird. Die ersten Sexualorgane treten bei schmalen Zellen $(16-30 \mu)$ bereits am nächsten Tage auf, falls letztere um $13 \mathrm{~h}$, also 4 Stunden vor Dunkelbeginn, der Lichtwirkung unterworfen wurde. Die Keimung der bei $15^{\circ} \mathrm{C}$ gebildeten Dauersporen wird bei $21^{\circ} \mathrm{C}$ in einigen Tagen erreicht.

\section{ENTSTEHUNG UND KEIMUNG DER DAUERSPOREN}

Dauersporen werden bei Diatomeen, und zwar fast ausschließlich zentrischen Arten nach sehr verschiedenen gattungs- und artspezifischen Modi gebildet, auf deren System an anderer Stelle eingegangen wird. Sie sind als Mittel anzusehen, um zum Wachstum ungünstige Situationen durch Eintreten in einen Zustand der Aktivitätsarmut zu überstehen. Das höhere spezifische Gewicht dürfte ein Absinken in Schattenzonen erleichtern. Die Fähigkeit, Sporen zu bilden, wird als ein äußeres Kennzeichen für den neritischen Status angesehen (z. B. GRAN \& ANGST 1931). Dieser Bewertung liegt wohl das Theorem zugrunde, daß nur in einer wenigstens zeitweilig beleuchteten Bodentiefe die Keimung der abgelagerten Spore, und vor allem das Wiedereintreten in den Planktonzyklus geschehen könne. Im ganzen scheint diese Annahme zu Recht gemacht zu sein. Die Keimung jedoch kann bei Stephanopyxis auch in völliger Dunkelheit erfolgen.

Wenn wir uns hier vorerst nur mit den Dauersporen von Stephanopyxis beschäftigen, so entstehen sie immer in Paaren (siehe auch Ostenfeld 1901, Bergon 1905, Hustedt 1930, Gran \& ANGst 1931), deren Mutterzellen in der Prophase nicht von der vegetativen Zelle gleichen Zustandes unterschieden werden können (Abb. 5), dasselbe gilt noch für die Zytokinese. Danach jedoch treten die Menisken etwas weiter auseinander als nach der vegetativen Teilung; die Valven werden dadurch kürzer, die verbindenden

${ }^{10} \mathrm{Da}$ Untersuchungen über die Größenabhängigkeit der Dauersporenbildung bei andern Diatomeen fehlen, gilt dieses bisher nur für die eine Art; auch vor Verallgemeinerungen in bezug auf die auslösenden Bedingungen muR gewarnt werden. 
Stacheln nachher länger (Abb, $5 g-j$ ) und dadurch bereits gibt sich die Teilung als eine heterovalvate, eine von den Schalen der Mutterzelle abweichend gestaltete Valven liefernde, zu erkennen. Diese Heterovalven werden in der Folge stärker verdickt; die Kammern sind höher und kräftiger konstruiert - ihr Porus ist schornsteinartig emporgezogen - und werden dadurch auch im optischen Schnitt durch die Schale hindurch erkennbar (Abb. 5l). Die Schalenbildung nimmt entsprechend mehr Zeit in Anspruch als diejenige der gewöhnlichen vegetativen Zelle ${ }^{11}$; die nächste Teilung setzt daher etwa 4 Stunden später ein, obwohl das prophasische Streckungswachstum nur etwa $2 / 3$ des Üblichen beträgt. Gegen Ende der Streckung beginnt jene eigentümliche Verlagerung der Plastiden in die Heterovalve, welche den Charakter der nun folgenden Teilung so augenscheinlich in ä qual macht. Die Verlagerung der Plastiden, von einer solchen des Zytoplasmas begleitet und möglicherweise durch sie verursacht, führt jene zurück bis auf eine Linie, die knapp jenseits der Gürtelfalz der zugehörigen Epitheca verläuft; fast an diese Linie wandert dann der Kern aus seinem Ort in der Heterovalve, der Hypotheca der Sporenmutterzelle (sensu strictu) und teilt sich nun in dieser auf den Zelläquator bezogen exzentrischen Lage. Die Furche schneidet dadurch die plastidenreiche Spore von einer äußerst plastidenarmen Zelle, die jedoch einen Todhterkern erhält, ab; letztere kann als Richtungskörper bezeichnet werden. Bei dieser Furchung lassen sich die bereits erwähnten Spontanplasmolysen außerhalb der Furche auf der Seite des Richtungskörpers beobachten. Sie führen dazu, daß letzterer eine zunächst meist linsenförmige Gestalt annimmt, wonach seine der Spore zugewendete Fläche eine feine, nahezu unstrukturierte und daher auch borstenlose Membran ausscheidet (Abb. 5r, links) oder auch nicht (Abb. 5r, rechts). Später rundet er sich ab und geht zuletzt zugrunde. Nur ungewöhnlich plastidenreiche Richtungskörper lassen sich gelegentlich zur Weiterentwicklung bringen. Auf der anderen Seite der Furche gestaltet sich eine Plasmaoberfläche, die denjenigen der vorangegangenen Teilung gleicht und eine ähnliche, meist noch etwas kräftigere Valva erzeugt. Die an dieser Schale entstehenden Borsten spreizen abweichend von gewöhnlichen Borsten und jenen des „Heterovalvenpaares“; sie sind außerdem länger und zugespitzt, wohl weil sie keine Partner haben. In der weiteren Entwicklung bricht das Sporenpaar an den Borstenköpfen auseinander und die Schalen der Paarmutterzelle lösen sich ab. Da die Sporenepivalva einen, wenn auch kurzen, etwa bis zum Hypovalvenscheitel reichenden Gürtel entwickelte, besitzt die Dauerspore die einer vegetativen Einzelzelle im Ruhestand entsprechende Schalenausruistung. Sie schafft sich großen Reichtum an Assimilaten. Die derben Dauersporen von Stephanopyxis-Arten werden gut erhalten und finden sich bereits in Ablagerungen der Kreidezeit, womit die Gattung als eines der ältesten erhaltenen Kieselalgengenera erscheint.

Die Keimung der Dauersporen exfolgt erwartungsgemäß (Abb. 6). Die Schalen öffnen sich in prophasischer Stredkung, dabei den hypovalvaren Gürtel ausbildend. Die erste Teilung des Keimlings ist dann wieder heterovalvat, wobei dieses Mal aber die Heterovalven gewöhnliche Schalen sind. Der nächste Teilungsschritt liefert neben

I1 Auch zu diesem Zeitpunkt ist die Determination zur Dauerspore nicht irreversibel. Nach Überführung auf $21^{\circ} \mathrm{C}$ sahen wir ein solches Paar je Zelle $z$ wei vegetative'Teilungszyklen durchfithren, aus denen insgesamt 7 Spermatogonangien und ein Oogon hervorgingen; dabei erhielt eines der ersteren und das Oogon die Heterovalven. 
zwei heterovalvaten die beiden ersten isovalvaten Zellen des Keimlings. Die Keimung bedarf nicht des Lichtes; aus den Reservestoffen der Spore allein entwickeln sich nacb unseren Erfahrungen auch im Dunkeln 4zellige Keimlinge. Der zeitliche Verlauf der Keimung im Licht entspricht wohl ebenfalls der Tatsache, daß eine Abhängigkeit von der Beleuchtung wegen der guten Versorgung mit Assimilaten nicht besteht. Ein Einzelfall $\left(21^{\circ} \mathrm{C}\right): 07.05$ Beginn der Streckung, 13.31 Teilung, 19.15 leichte Streckung der Tochterzellen, 23.20 Teilung der einen, 23.44 Teilung der anderen Tochterzelle; 06.34 3 der 4 Zellen beginnen sich zu strecken. Die Teilungsintervalle sind also sehr verkürzt.

Ganz wie Stephanopyxis turris stellen auch die Warmwasser-Art S. palmeriana nach Gran \& ANGST und ähnlich unter den übrigen Centrales nach Gran (1900) Melosira arctica ihre Sporen her. Nicht viel anders, jedoch in den Modalitäten der Schalenbildung abweichend, erfolgt die Bildung der Zellpaare mit "Doppelschalen" bei der Pennaten Meridion circulare (Gertler 1963), nur daß bei ihr die Ausscheidung der Innenschalen am Richtungskörper ganz unterbleibt. Die erste Teilung der Paarmutterzelle kann nur insofern als heterovalvat bezeichnet werden, als die (hier posttelophasische) Ausbildung der Gürtel ganz unterbleibt, also nur Valven entstehen und als diese eine etwas kräftigere Struktur zu besitzen scheinen. Die zugehörigen Unterschalen sind stärker abgewandelt. Nach den ökologischen Angaben ist es nicht unmöglich, daß es sich ebenfalls um Dauerzellen handelt, welche der Uberwindung der ungünstigen warmen Jahreszeit dienen; dafür würde auch der Assimilatreichtum sprechen. Die Schalen dieser Sporen blieben dann nur ungewöhnlich dünn; doch existieren bei den beiden marinen Pennales Fragilaria oceanica und Acbnanthes taeniata (MEUnIER 1910, HuSTEDT 1930) Zellpaare mit ähnlicher Genese, deren dickwandige Schalen an der Dauersporennatur keinen Zweifel lassen; unsicher ist hier nur, ob die Sporenhypovalven durch Inäqualteilung oder wie bei Chaetoceros (siehe unten) azytokinetisch entstehen.

Der Vorgang der Dauersporenbildung in seiner speziellen Form hat wohl den „Sinn“, innerhalb der entwicklungsmechanischen Potenzen einer primitiven Diatomeengattung möglichst viel Plasma in den engen Raum der Spore zu bringen; nur der Richtungskörper wird dabei "geopfert". Moderne Formen, soviel sei noch zur vergleichenden Entwicklungsgeschichte hinzugefügt, vermeiden dieses Opfer; auch wenn die Dauersporen (etwa bei Chaetoceros didymus) paarweise wie diejenigen von Stephanopyxis entstehen, lassen sie das Plasma der Sporenmutterzelle zur Heterovalva hin kontrahieren und scheiden danach an der neuen Plasmaoberfläche die Hypovalva der Spore aus. Bei den meisten Arten dieser Gattung werden übrigens b e i d e Valven der Dauerspore an durch je eine lokalisierte Plasmolyse exponierten Rückzugsflächen, also a $z$ y t o k in e $t$ is $\mathrm{ch}$ gebildet. Daß es sich dabei um rudimentierte Zellteilungen handelt, zeigten Beobachtungen an C. teres. Während der Plasmolyse, welche der anaphasischen Erschlaffung in der Zytokinese entsprechen dürfte, läuft eine Kernteilung ab; von der Zytokinese ist also nur die anschließende Schalenbildung übrig geblieben. Beide Kerne bleiben im gleichen Zytoplasten und einer von ihnen geht unter Pyknose zugrunde. Dieses Verhalten wiederholt sich bei der Bildung der anderen Valve. Es handelt sich um einen Spezialfall der von GeItLer (1963) aufgefundenen Gesetzmäßigkeit: "Alle Schalenbildungen der Diatomeen treten als Folge von Zell- oder Kernteilungen auf." Die Umkehrung gilt, wie beispielsweise die Gametogenese von Stephanopyxis zeigt, nicht. 
Die Schalenentstehung in der Auxospore geht bei Diatomeen in der gleichen Art vor sich wie die Dauersporenbildung in einer Sporenmutterzelle von Chaetoceros teres. Auch Stephanopyxis bedient sich dieser, oben als phylogenetisch fortschrittlich bezeichneter Methode, welche sie merkwürdigerweise bei der Dauersporenbildung "noch" nicht verwendet. Die Keimung wurde bisher nur von Michailowa (1962) bei Chatoceros beschrieben, wo sie ähnlich wie bei Stephanopyxis ein vegetatives Austreiben ist, allerdings unter Abstoßung, nicht Einbeziehung in den Keimling, der Sporenmembranen. Die Beobachtungen von Gross $(1937,1939$ a, b) an Ditylum beziehen sich, entgegen der von diesem Autor vertretenen Ansicht, nicht auf Dauersporen (v. Stosch 1965).

\section{ENTWICKLUNG DER SEXUALZELLEN, BEFRUCHTUNG UND AUXOSPORENBILDUNG}

Aus schmalen vegetativen Zellen ( 16 bis $30 \mu$ ), bei denen der Sexualisierungsdruck hoch ist, können sowohl Spermatogonangien (männliche Gameten ausbildende Zellen) als auch Oogonien (weibliche Gameten ausbildende Zellen) direkt, also ohne dazwischen geschaltete Teilungen hervorgehen. Breitere Zellen machen unter unseren Bedingungen jedoch vorher noch mindestens eine Zellteilung durch. Das zeigen Induktionsversuche, bei denen im Schwachlicht (200-300 Lux $/ 15^{\circ} \mathrm{C}$ ) befindliches vegetatives Material unter Bedingungen gebracht wird (Belichtungs- und Temperaturerhöhung: $4000 \mathrm{Lux} / 21^{\circ} \mathrm{C}$ ), die rasch Sexualzellen hervorrufen (Drebes unpubl.). Schmale Zellen können durch den Bedingungswechsel, nach minimal 4 Stunden, am Ende der Lichtperiode gegeben, festgelegt sein, was am Ende der anschließenden Dunkelperiode äußerlich erkennbar wird; bei breiteren Stämmen und schmalen Klonen in der Mehrzahl ihrer Zellen verschiebt sich die Festlegung um 24 Stunden; unsere Schilderungen beziehen sich meist auf letztere. Im weiteren verlaufen beide Entwicklungen verschieden, indem das Oogon direkt zur Oozyte wird, das Spermatogonangium aber erst durch mehrere Teilungsschritte die

Abb. 8: Einzelbilder zur Mitose. $a$ Metaphase, $b$-e Anaphase bis beginnende Furchung im optischen Schnitt; in $b-d$ Spindel erkennbar, unter dieser in $c$ und $d$ Plasmapolster; $f-i$ Anaphasen in Aufsicht; $f$ Plasmabrücke schnürt sich durch, dahinter Spindel; $b$ Spindel allein verhindert die Tochterkerne; $j$ und $k$ Furchung spät, im optischen Schnitt. Spindel mit den beiden Kernen am Ende hängt sattelartig uber der Furche. Da die Spindel nicht parallel zur Zelllängsachse liegt, erscheint in $j$ durch Becke-Eftekt der linke Kern dunkel, der rechte hell; $k$ Spindel freigelegt, nach oben elastisch durchgebogen

Abb. 9: Bilder zur Zytologie von Stephanopyxis. a Ruhekerne, $b$ vegetativer Kern in Präprophase, $c$ Oogonkern noch in Valva (Präleptotän), $d$ Mitose (Metaphase), e Mitose (Anaphase), $f$ Oogon (Zygotän), g Spermatozyte (Metakinese von Meiosis I.). Ein Teil der Chromosomen ist bereits in die Spindel eingeridkt (unten rechts drei, oben links ein Chromosomenpaar noch frei), Diakinesekonfigurationen; $b$ Spermium, noch im Spermatogon (Kern nahezu homogen); vergleiche Durchmesser mit a (vegetativer Kern) und ( (Zygotenkern); $i$ beginnende Kernpyknose (rechter Kern) in der Valva nach der "Häutung" einer vegetativen Zelle; $;$ Spermakern am Eikern im Oogon (Achromasie des Eikerns), rechts zweiter, links erster pyknotischer Kern (1); $k$ Kernyerschmelzung fortgeschritten, links am Eikern erster, rechts zweiter pyknotischer Kern; l späteres Verschmelzungsstadium. Eikern noch immer achromatisch, die männlichen Chromosomen (gespalten!) "diffundieren" in den Eikern hinein. Eikern mit, Spermiumkern (rechts) ohne Nukleolus; $a, d, e-i, l$ haben gleichen Maßstab, ebenso $b, c$ und $j$ 


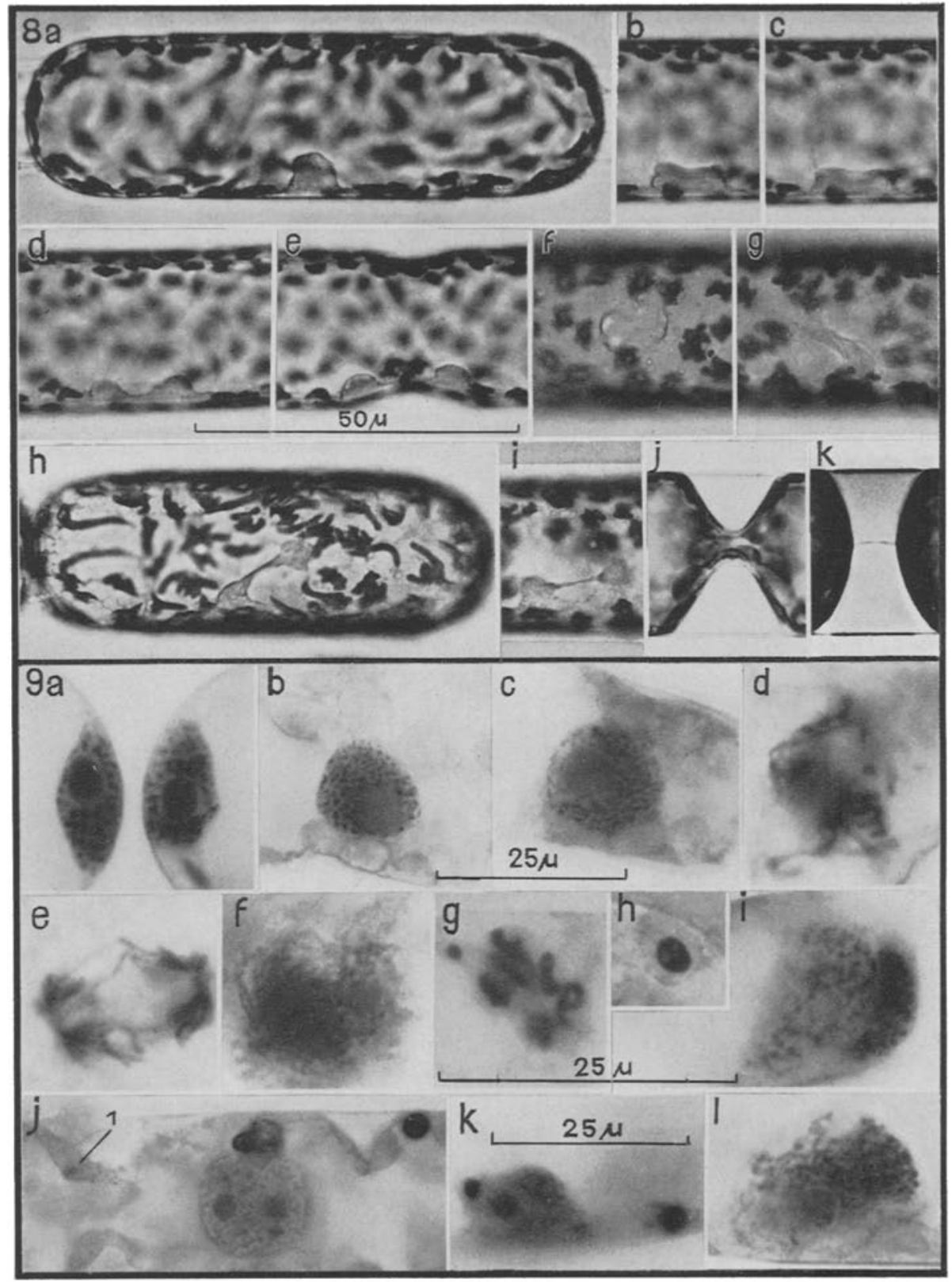


Spermatogone differenziert; letztere können nach Beginn der Meiosis als Spermatozyten bezeichnet werden.

\section{Enstebung der Spermien}

\section{Die Differenzierung der Spermatogonien}

Spermatogonangien sind im noch ruhenden $Z$ ustand naturgemäß dann von gleicher Länge (Abb. 10a, b) wie vegetative Zellen, wenn sie direkt aus diesen entstehen, geschieht dieses nach einer oder mehreren Teilungen, so erscheinen sie häufig verkürzt. Der Mechanismus ist eine geringere Streckung in der Einleitung der Teilung mit dem Ergebnis, daß nur Valven verminderter Länge im Raum des Gürtels Platz haben, wie dieses die Beispiele von Abbildung 10 zeigen. Die für die männliche Entwicklung charakteristische Bildung extrem kurzer Zellen, der Spermatogonien, wird hier für

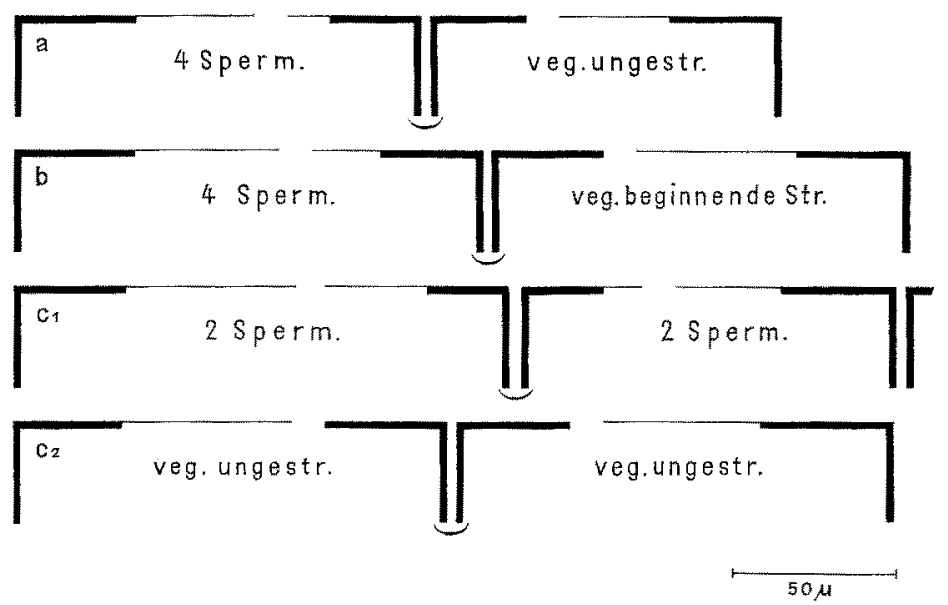

Abb. 10: Abmessungen der Schalen von männlich differenzierten und vegetativen Zellen. Senkrechte Linien: Breite, horizontale Linien: Länge; Valven dick, Gürtel dünn ausgezogen. Bei den Spermatogonangien ist die Zahl der bereits differenzierten Spermatogonien, bei den vegetativen Zellen der Streckungszustand vermerkt (Schalen der vegetativen Zellen auseinandergezogen gezeichnet). Die Hypopleura der Spermatogonangien ist kürzer als die Epipleura. $c_{1}$ und $c_{2}$ ein Faden, hier sind auch die Hypovalven der Spermatogonangien beträchtlich kürzer als diejenigen des vegetativen Nachbarzellpaares: vorwegnehmende Differenzierung

deren Mutterzellen, die Spermatogonangien, vorweggenommen. Abbildung 10 zeigt auch, daß von zwei Schwesterzellen beide gleichzeitig (c) oder nur eine $(a, b)$ männlich differenziert werden können.

Das Stredkungswachstum des Spermatogonangiums setzt früher ein als das einer vegetativen Schwesterzelle, mitunter schon am Ende der Dunkelphase. Dieser Sachverhalt wird wiederum belegt durch Abbildung 10, in welcher die Spermatogonangien schon im 2- (Abb. 10c) oder 4-Zellen-Stadium sind ( $a, b)$, während die vegetativen Nachbarn noch nicht einmal oder eben erst $(b)$ die Streckung begannen. Das Stredkungs- 
wachstum erreicht bis zur ersten Zytokinese nur etwa $1 / 3$ des Wertes einer vegetativen Teilung (Tab. 2); entsprechend wurde die Hypopleura meist weniger als halb so lang als die Epipleura, und die erste Teilung im Spermatogonangium setzt gegenüber der vegetativen Zellteilung weiter verfrüht ein. Nunmehr folgen, nicht ganz streng synchron, eine oder zwei weitere Zytokinese-Wellen, welche 4 oder 8 Spermatogonien entstehen lassen. Diese leiten dann die Meiosis ein und werden damit zu Spermatozyten.

Die Differenzierungsteilungen sind in mehrfacher Hinsicht bemerkenswert. Die Generationsdauer der erzeugten Zellen ist mit 3 Stunden $\left(21^{\circ} \mathrm{C}\right)$ gering. Dem entspricht eine "flüchtige" Ausbildung der neuen Membranen, ihre Valven bleiben zart und entbehren meist einer Ornamentierung durch Areolen und immer einer solchen durch Stacheln. Sie sind aber schwach verkieselt und tragen in einer Eindellung am Scheitel ein rundes Auge. Da die Beträge der Streckung von Teilung zu Teilung abnehmen (Tab. 2), werden die Pleuren progressiv kürzer und können an den letztgebildeten Schalen ganz fehlen.

\section{Tabelle 2}

Streckungsbeträge der Mitose und bei den Vermehrungsteilungen der Spermatogonien (32 $\mu$ Breite). Spermatogonangium von Abbildung $11 a-k$

\begin{tabular}{|ccccc|}
\hline Vegetative Mitose & & Spermatogonangium: & Streckung \\
& 1. Mitose & 2. Mitose & 3. Mitose & Spermatogonan \\
& & Streckung & Streckung & gium ingesamt \\
$72 \mu$ & pro Zelle & pro Zelle & $43,6 \mu$ \\
\hline
\end{tabular}

Auch die Form der Valven wird durch Reduktion des Mantels und eine Abnahme in der Wölbung des Diskus fortschreitend vereinfacht. Die Furchen schneiden, wohl durch die geringe Pleuralänge bestimmt, so schmal ein, daß die Spindel anschließend die Menisken fast ebnet und die posttelophasische Auswölbung danach gering bleibt. Jede dieser Teilungen ist in bezug auf die Schalen der vorangegangenen etwas heterovalvat und insbesondere die letzte auch stark inäqual (Abb. 11k), da dem Anschein nach die Kernlage, welche ihrerseits den Ort der Furche bestimmt, an der Gürtelfuge orientiert wird (Abb. 11i), und da diese letzte wegen des fehlenden Eigengürtels und der geringen Wölbung der jüngsten Schalen exzentrisch in bezug auf die Spermatogonpole liegt. Bei sehr schmalen Zellen sind (bezogen auf die Breite) die relativen Streckungen größer und daher merkliche Valvenmäntel an den Spermatogonienschalen entwickelt. Wenn man vom Fehlen der Borsten absieht, entspricht die Valvenform der Spermatogone derjenigen einer um einen beträchtlichen Betrag breiteren vegetativen Zelle. Seltener und dann meist auch nur bei einigen der 8 Zellen teilt sich der Kern noch einmal mitotisch; die Zytokinese "gelingt" dann aber in den meisten Fällen nicht: es entstehen 2kernige Spermatozyten, welche später 8 Spermien liefern. Schließlich verhalten sich auch die Plastiden dadurch ungewöhnlich, daß sie nur noch vor der ersten Teilung vermehrt werden. $\mathrm{Da}$ die Zahlen gegenüber denjenigen in vegetativen Zellen etwas niedrig sind (116 \pm 18 gegen $138 \pm 25,6)$ scheinen bereits früher einzelne Plastiden ungeteilt geblieben zu sein. Danach werden die Chloroplasten lediglich auf 
die Spermatogonien aufgeteilt und gehen gleichzeitig an Größe und Farbstoffgehalt zurück. Dieser Schwund an Plastidensubstanz ist ein Charakteristikum aller Diatomeenspermatogenesen; er findet sich selbst bei der oogamen Pennatengattung Rhabdonema (v. Sтоsсн 1958a). Zur Deutung dieser Tatsache könnte man überlegen, daß die gesamten Differenzierungsvorgänge also 3 bis 4 Teilungsschritte von der vorhergehenden vegetativen Teilung an gerechnet, kaum mehr Zeit brauchen, als es der Generationsdauer der vegetativen Zelle entspricht; in diesem Zeitraum wird aber vermutlich (Messungen fehlen) die 4fache Menge DNS produziert; so könnte der Baustoff- und Energiebedarf dieser Synthesen auf Kosten der Plastidensubstanz, jener, welche nicht aufgebaut wird sowie jener, welche verschwindet, gehen. Die Plastiden sind ohnehin „überflüssig“, sie werden nicht für die Spermien benötigt. Schließlich sei bemerkt, daß auch die Nukleolen während der Spermatogonienteilungen verschwinden, was übrigens wieder bei anderen Diatomeen vorkommt.

Nach der letzten diploiden Mitose „ruhen“ die Spermatozyten etwa 5 Stunden; während dieser Zeit laufen die verwickelten Vorgänge der meiotischen Prophase ab, und treten dann in die Reduktionsteilungen ein.

Wenn wir die Spermatogonienentstehung der Stephanopyxis vergleichend entwicklungsgeschichtlich einordnen, so sind die Prozesse in ihren Grundelementen überall bei Diatomeen ähnlich: Durch differenzierende Teilungszyklen entstehen in unterschiedlichem Maße vereinfachte und an Größe, morphologischer Ausstattung sowie Plastidenund Farbstoffgehalt geminderte Zellen. Man kann also von d e p a u p r i e re n d e n Teilungen sprechen, die im einzelnen sehr verschieden weit reduzierte Zellen liefern. Dabei lassen sich zwei Gruppen unterscheiden: Bei den Melosira-Arten sind die Einzelspermatogonien noch frei und ihre Schalen zwar kürzer und dünner als die vegetativen, aber sonst vollständig. Auch Formen, welche wie Cyclotella eine deutliche Differenzierung der Spermatogonien nicht erkennen lassen (GEITLER 1952) wären hier einzuordnen. Die Zellzahl schwankt in den aus einer Mutterzelle hervorgehenden Gruppen von Spermatogonien sehr stark, bei Melosira varians zwischen 2 und mindestens 16 . Bei der zweiten Gruppe dagegen trennen sich die Schalen der Mutterzelle erst kurz vor oder nach Fertigstellung der Spermatogonien, die zwischengeschalteten Teilungszyklen sind entsprechend durch geringes oder fehlendes Streckungswachstum charakterisiert. Die Spermatogonien werden in ihrer Ausstattung stärker vereinfacht und weichen von der Mutterzelle in zahlreichen Merkmalen ab. Diese ist zum Spermatogonbehälter geworden und kann daher als $\mathrm{S}$ p e r $\mathrm{m}$ a t o g o n a $\mathrm{g}$ i $\mathrm{u}$ m bezeichnet werden.

Stephanopyxis turris, Biddulphia rhombus und B. granulata bilden die Schalen der Spermatogonien in vereinfachter Form noch aus (v. STosch 1956). Bei B. mobiliensis, B. regia und B. sinensis (z. B. Bergon 1905, Schmidt 1927, v. Stosch 1954a)

Abb. 11: Androgenese von Stephanopyxis, a-k bilden eine Beobaditungsserie, $l-s$ (mit Ausnahme von $m$ und $r$ ) eine zweite. Uhrzeit angegeben. $a$ Spermatogonangium gestreckt; $b$ erste, $f-g$ weite, $j, k$ dritte Differenzierungsteilung; $m$ Ausschüttung der Spermatogone durch die der später meiotischen Prophase zugeordnete rasche Schwellung, n Rückgang der Schwellung (Meta- und Anaphase I); $o$ frühe und $p$ späte Interkinesen und (oben) frühe Anaphasen II, $r$ Anaphase I, stärker vergrößert (Spindel!); $q$ Ablösung der Spermien vom plasmarischen Restkörper beginnt an zwei Spermatozyten; beachte Spermatogonschalen; $s$ ein Spermium fast abgelöst (Mitte); $a-s$ (mit Ausnahme von $r$ ) im gleichen Maßstab; $t$ Ablosung der Spermien vom Restkörper 


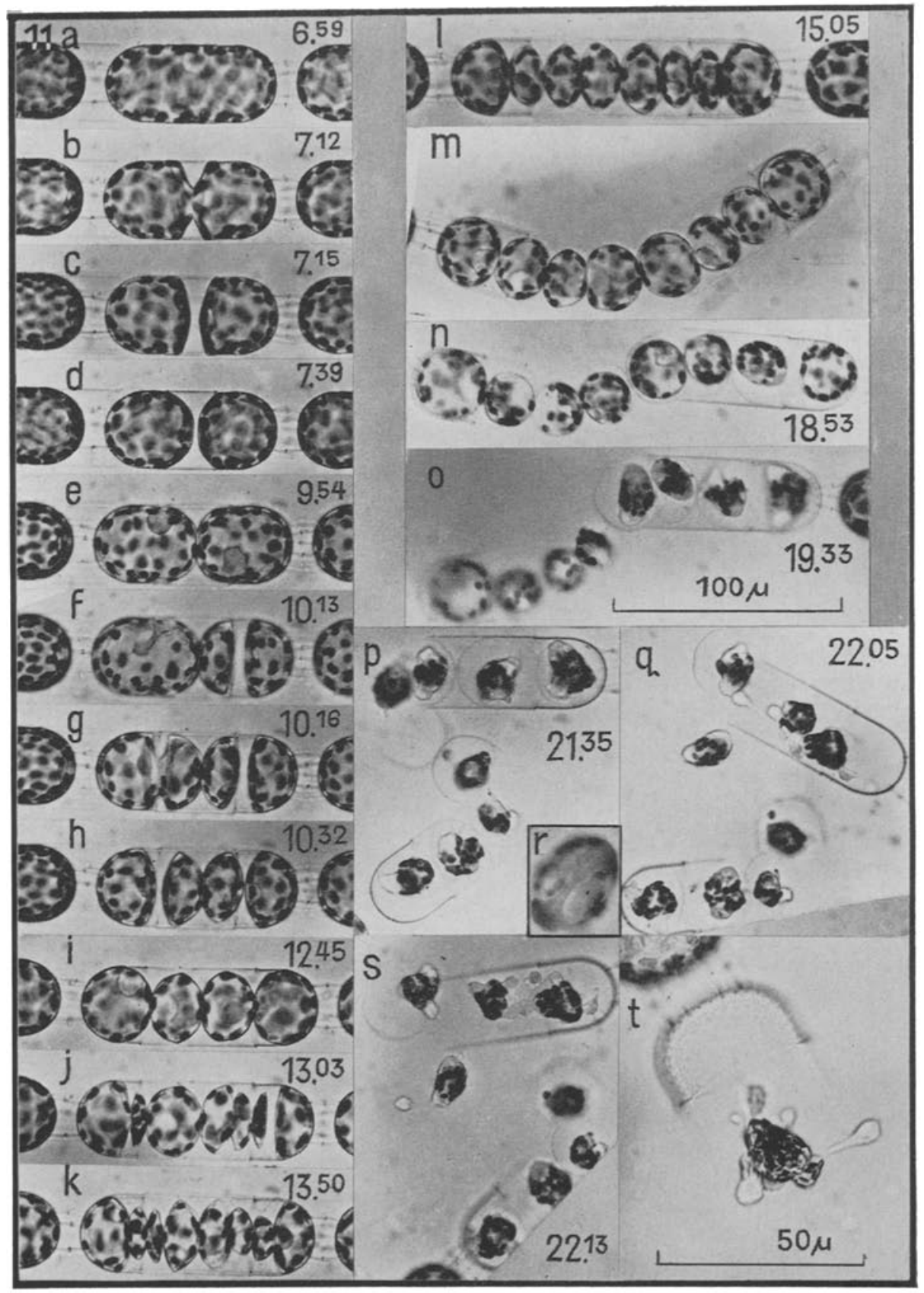


werden Schalen nur noch von der ersten Differenzierungsteilung geliefert; die zahlreichen relativ kleinen Spermatogonien sind ähnlich wie bei folgenden Arten, welchen jegliche Schalen innerhalb des Spermatogonangiums fehlen, nackt: Lithodesmium, Streptotheca und Bellerochea (v. Sтолсн 1954a, bezüglich der letzten Art siehe auch Subrahmanyan 1946), Rbizosolenia setigera (v. Stosch unpubl.), Chaetoceros-Arten (z. B. Murray 1897, Gran \& Angst 1931, v. Stosch unpubl.) und die großen Coscinodiscus-Arten (Pavllard 1914, Hofker 1930, v. STosch unpubl.). Schließlich können auch noch die Zytokinesen nach den Vermehrungsteilungen in den Spermatogonangien ausfallen; die Spermatogonien sind in diesem durch Guinardia flaccida und Anlacodiscus argus belegten Falle nur noch in der Form ihrer in einem Plasmodium vereinigten Kerne repräsentiert (v. STOScH unpubl.).

\section{Meiosis und Spermiogenese}

Die summierten Streckungen von Spermatogonangium und Spermatogonien hatten die Schalen des ersteren nur gerade geöffnet. Die Zellgruppe wird aber noch zusammengehalten, weil die Schalen der Mutterzelle auf eine Spermatogonschale aufgeklemmt bleiben. Während der etwa ersten $3 \frac{1}{2}$ Stunden der nun folgenden Teilungsruhe geschieht bis auf eine langsame Streckung der Spermatogonangien äußerlich nichts; danach schwellen die Spermatozyten rasch und stark an und drücken mittels ihrer Eigenschalen die Spermatogonangiumhälften auseinander und danach die den Mündungen der Behälterhälften zunächstliegenden Spermatozyten aus diesen heraus (Abb.11m). Die Schwellung hat nach zwei Stunden ihren Höhepunkt erreicht und beginnt darauf in den einzelnen Spermatogonien ziemlich ungleichzeitig wieder nachzulassen. Die Schwellung entspricht der Prophasestreckung und die darauf folgende Erschlaffung vermutlich dem metaphasischen Turgeszenzverlust bei der vegetativen Teilung. Dabei lösen sich die Protoplasten der Spermatozyten von ihren Schalen und runden sich ab. Die Zellen treten damit in die meiotische Metaphase ein (Abb. 11n, vierte Zelle von rechts). Während der ersten meiotischen Teilung sinkt nun die Vakuole immer mehr zusammen und ist dann gegen die späte Anaphase hin meist nicht mehr zu erkennen.

Zum Unterschied zur Mitose wird während der Anaphase von Meiosis I nicht einmal die Andeutung einer Furche sichtbar; es entsteht ähnlich wie bei den MelosiraArten (v. Stoscr 1951, 1958) ein Plasmodium, dessen beide Kerne nunmehr sidh als helle Kuppen abzeichnend an die Pole des jetzt breit spindelförmigen Protoplasten treten. Etwa eine Stunde nach der Metaphase beginnen an diesen Polen je zwei Geißeln als kurze Stummel auszuwachsen und sich dann weiterzuverlängern. Zu diesem Zeitpunkt sind die Protoplasten stark amöboid in ihrer Gestalt und neigen dazu, keulenförmige Pseudopodien auszusenden. Häufig kommt es dabei zu bedeutender Streckung der Spermatozyte und zu knospenartiger Abhebung der Interkinesekerne vom Hauptprotoplasten.

Das Einsetzen der zweiten Teilung, das weitere zwei Stunden später liegt, wird zuerst an dem Auseinanderrücken der Geißeln jedes Paares erkennbar. Dieses entspricht wahrscheinlich der Ausbildung der Spindel, mit deren Polen die Basalkörner in Beziehung zu stehen scheinen, eine Beziehung, die aber noch bei keiner Diatomee mit zytologischen Methoden näher definiert wurde. Die Spindel führt die Chromosomen 
in der Metaphasenanordnung; wahrscheinlich entspricht ein zwischen den Geißeln stehender Höcker der einen Seite dieser Platte mit ihrer Plasmaumhüllung. Dieser Hügel verbreitert seinen Gipfel (Abb. 11p oben; erste und dritte Zelle von rechts) während der Anaphase, bis in seiner Mitte eine Einsenkung entsteht. Schließlich ragen vier kernhaltige, aber plastidenfreie Knospen an den Ecken eines tetraedrischen Körpers hervor, in dem die Plastiden geballt liegen (Abb. 11s, 1. u. 2. Zelle von rechts).

Die prophasische Streckung der Spermatozyten hatte zunächst nur das Spermatogonangium geöffnet, die in ihm enthaltenen Zellen aber mehr oder minder intakt gelassen. Deren Offnung wird nunmehr (Abb.11p, q) anscheinend durch den Geißelschlag während der Interphase oder auch erst nach der zweiten Teilung besorgt. Die Spermatozyten-Plasmen werden daher von der späten Interphase an zu verschiedenen Zeitpunkten frei, die in oder nahe der Spermatogonangien-Valven liegenden zuletzt; vielfach befreien sich hier aber erst die selbständig gewordenen Spermien.

Die Loslösung der Spermien von dem plasmatischen, alle Plastiden behaltenden Restkörper erfolgt relativ spät nach der zweiten Teilung (Abb. 11q, s, $t$ ). Der Eindrudk ist derjenige einer Befreiung durch den Zug der nunmehr außerordentlich heftig schlagenden Geißel, welche die Spermienkörper, den Kern mit einem schwachen Plasmaleib, vom Restkörper abzieht. Dabei wird das Hinterende des Spermiums zu einem langen Faden ausgesponnen. Es mögen bei der Ablösung aber außerdem Oberflächenkräfte, ähnlich denjenigen, welche die Furchung in der Zellteilung vollziehen, beteiligt sein; die Druckspindel scheint bei Stephanopyxis keine Hilfestellung zu leisten. Nadh der Befreiung schwimmen die Spermien sogleich mit großer Geschwindigkeit ab, der Restkörper geht später zugrunde.

Zytologisch ist die Differenzierung der Spermatogone durch das Verschwinden des Nukleolus und eine Verdichtung des Kerns ausgezeichnet, was beides bei anderen Diatomeen seine Parallele hat. Eine genaue Synchronisierung der Stadien der Meiosis an den Streckungsverlauf der Spermatogonien ist im Augenblick nicht möglich, doch dürfte bereits während der Phase der langsamen Schwellung, schätzungsweise 11/2 bis 2 Stunden nach der letzten Differenzierungsteilung, das Leptotän beginnen und in der Phase der raschen Schwellung die Kerne sich in Diakinese befinden. Die meiotischen Kerne sind merklich kleiner als im Ei. Auf Schilderung der Einzelvorgänge wird verzichtet. Die Kerne der Spermien zeigen sich wie bei den Biddulphien (v. STosch 1954, 1956) und im Gegensatz zu Melosira varians (v. STosch 1951) und Cyclotella (GeITLER 1952) hoch kondensiert, nahezu homogen (Abb. 9h).

Die vergleichende Betrachtung der Spermiogenese ergibt zunächst für den Gesamtvorgang eine m e ro g e n e Natur (v. Sтоsса 1954a). Nicht das ganze Spermatozytenplasma wird für die Spermien verbraucht, sondern durch die Fünfteilung bleibt die Hauptmenge des Plasmas mit allen Plastiden zurück, nachdem Meiosis I ohne Plasmatomie ablief. Im Gegensatz dazu steht Biddulphia granulata (v. SToscH 1956), bei welcher eine Plasmatomie erfolgt und daher neben den 4 Spermien 2 Restkörper entstehen. Auf die bei Diatomeen mit nackten Spermatogonien verbreitete holog e n e Spermiogenese, die alles Plasma einbezieht und in beiden Schritten zytokinetisch verläuft, braucht nur insofern eingegangen zu werden, als sie das Verhalten der Plastiden betriff, die hier viel weiter in der Größe reduziert werden und dann zur Masse des Spermienkörpers kaum noch beitragen. Plastiden sind also anscheinend überflüssig; sie wer- 
den im Restkörper gelassen oder rückgebildet, in einem noch nicht von uns beschriebenen Falle (Coscinodiscus granii) sogar einzeln abgestoßen. Der hier geschilderte Typus der merogenen Teilung, welche bei Melosira (v. STOSCH 1958) bereits bekannt gemacht wurde, findet sich ähnlich noch bei den Coscinodiscaceen Actinocyclus ebrenbergï und Actinoptychus undulatus (v. Sтоsсн unpubl.). Im Vergleich zu der von diesen Arten allein genauer geschilderten Melosira moniliformis fällt der größere Zeitverbrauch bei der Ablösung der Spermien auf. Dieses scheint bedingt durch die hervorstechende Beteiligung der Spindel bei Melosira, die, unterstützt vermutlich von „Furchungskräften“, die Spermien bereits im Zuge ihrer Anaphasestreckung fast simultan vom Plasmarest abdrückt, während sie beim jetzigen Objekt nur die Verteilung auf der Spermatozytenoberfläche besorgt, die Befreiung der Spermien aber wohl in erster Linie dem Zug der Geißelmotorik ïberläßt.

Allen bisher untersuchten Centrales gemeinsam ist das paarweise Auswachsen der Geißeln in der Interphase und die endgültige Eingeißeligkeit der Spermien.

\section{Oogone und Auxosporen}

\section{Differenzierung der Oogone und Prophase der Meiosis}

Im. Gegensatz zu den durch depauperierende Differenzierungsteilungen entstehenden Spermatogonien können sich die weiblichen Sexualzellen, die Oogonien, welche dann später mit dem Eintritt der Meiosis als Oozyten bezeichnet werden müßten, direkt aus der vegetativen Zelle entwickeln. Breitere $(>30 \mu)$ Zellen sowie die Mehrzahl derjenigen schmaler Populationen teilen sich jedoch, soweit sie zu Oogonien werden, mindestens einmal, bevor sie determiniert sind. Die Schwesterzelle eines Oogons kann dabei vegetativ bleiben und sich teilen; sie kann auch selbst zum Oogon oder auch zum Spermatogonangium werden. Das Oogon ist bereits in ungestrecktem $\mathrm{Zu}$ stand durch seine erhöhte Plastidenzahl $(190,4 \pm 9,51$ gegen $138 \pm 12,8$ der vegetativen Zelle; $32 \mu$ Zellbreite) zu erkemnen. Der Kern ist etwas stärker angeschwollen und liegt nicht wie bei der gewöhnlichen Zelle fest, sondern pendelt um das Diskuszentrum. Praktisch ist es allerdings in diesem Zustand nicht immer möglich, ein Oogon sicher anzusprechen.

Die Streckung beginnt im Durchschnitt etwa 1 Stunde später als diejenige zur vegetativen Teilung, schreitet langsamer fort und hält länger an, nämlich für 7 bis 8 Stunden. Sie führt meist zu höheren Werten der Gürtellänge, was im wesentlichen auf einer Verlängerung der Hypopleura, also verstärktem Streckungswachstum beruht, die Hypopleuren vegetativer Zellen eines Materials von $32 \mu$ Breite maßen 44,2 \pm $3,54 \mu$ diejenigen der Oogonien 56,4 $\pm 4,32 \mu$. Der Kern beginnt zu wandern, wenn etwa $1 / 3$ der Streckung vollzogen ist und erreicht bald die Region des Zelläquators, wo er nicht festliegt, wie in der Mitose, sondern hin- und herrutscht, und er wird auch meist außerhalb einer exakten Aquatoriallage von der meiotischen Karyokinese erfaßt. Diese Unruhe des Kernes ist für die Meiosis charakteristisch. In einem Falle wanderte er sogar aus der Hypovalva durch die ganze Zelle und kehrte in die Hypovalva zurück. Die Kerne fallen im Zustand der Voll-Streckung gegenüber der Mitose durch Größe und stärkere Abrundung (Abb. 13a) auf, die relativ dicken Chromosomen 
in ihnen - sie dürften in Diakinese sein - sind auch im Leben deutlich zu erkennen. Ferner zeichnet sich das Oogon durch Plasma- und Pigmentreichtum aus, kleine O1tröpfchen sind häufig vorhanden (Abb. 12).

\section{Meiosis und Kernabort}

Die meiotischen Teilungen setzen in den im Wechsellicht bei $21^{\circ} \mathrm{C}$ gehaltenen Kulturen etwa ab 17 Uhr ein, also um die gleiche Zeit oder etwas früher als diejenigen in den Spermatozyten, so daß die Oogone befruchtungsfähig sind, wenn die Spermien frei werden. Beide Entwicklungen sind durch eine Lichtwechsel-Synchronisierung, die hier schärfer ist als in der Mitose, aufeinander abgestimmt, was bei der Kurzlebigkeit der Spermien auch als notwendig erscheint. Im Prinzip Gleichartiges kennt man auch bei Sexualzellen anderer Meeresalgen (z. B. Dictyota) (BünnIng \& Mürler 1961, BüNNING 1963), deren Entleerung nicht nur zu bestimmter Tageszeit, sondern in einer weiteren Synchronisierung relativ zur Mondphase auch nur an wenigen Tagen des Monats geschieht.

An dieser Stelle sei ein Wort über die Karyologie der weiblichen Meiose eingeschaltet. Das frühe Leptotän scheint bereits bei Beginn der Streckung vorzuliegen (Abb. 9c). In den nachfolgenden Kernstadien findet man den Kern meist mehr oder weniger in Gürtellage. Zygo- und Pachytän sind leicht und zahlreich zu sehen (Abb. 9f). Die Diakinesegemini bleiben scharf umschrieben und relativ, wenn auch verschieden lang. Sie besitzen meist mehrere Chiasmen. Ihre Zahl beträgt etwa 14. Die Einordnung in die Spindel scheint wie bei anderen Centrales und wie dies Geitler (1956) für Cymbella aspera beschrieb, stark sukzedan zu erfolgen (Abb. 9g). Nach der ersten Karyokinese wird ein vollständiger Ruhezustand des Kerns hergestellt.

Eine Stunde vor Einsetzen der Anaphase beobachtet man einen Gestaltwechsel des Kernhïgels, der seine rundliche Form verliert (Abb. 13b) und im Umriß „amöboide" Formveränderungen durchzuführen beginnt. Das beruht vermutlich einmal auf einer tatsächlichen Amöboidie des hier angesammelten Plasmas, zum anderen auf dem Schwinden der Kernmembran bei einsetzender Metakinese, der Einordnung der Chromosomen in den Spindeläquator, die also von langer Dauer wäre. Die Teilungen selbst verlaufen mit stärker als in der Mitose zur Zellachse geneigter Spindel (Abb. 13c, d), und zwar ohne anschließende Zytokinese. Jedoch beobachtet man als Aquivalent zur Furchung häufig eine metaphasische Erschlaffung des Protoplasten, der sich dann in der Gürtelregion von der Membran leicht abhebt. In Gegensatz zu den Spermatogonien erfolgt aber Kernabort nach jedem Teilungsschritt und das Oogon ist zuletzt einkernig. Dieser Vorgang ist bereits von zahlreichen anderen Diatomeen aus fxierten Präparaten bekannt, bei der zur Beobachtung günstigen Stephanopyxis kann er im Leben gesehen werden und offenbart sehr merkwürdige Züge.

Die Spindel, klar erkennbar, schiebt, sich verlängernd, die Tochterasteren im plasmatischen Wandbelag auseinander (Abb. 13c, d). Die Bewegung kommt etwa 6 bis 7 Minuten nach ihrem Beginn zum Stillstand. Nach einiger Zeit ( $7-16$ Minuten), die Spindel ist dann anscheinend resorbiert, bewegen sich die Kerne mit einer der des Anaphasestretch etwa entsprechenden Geschwindigkeit aufeinander zu (Abb. 13e,f). Die dieses motivierenden Kräfte sind unbekannt; jedenfalls genügen sie, um gelegent- 
lich Plastiden aus dem Verband im Wandbelag heraus und vor dem wandernden Kern herzuschieben. Nichts spricht für die Tätigkeit von Plasmaströmungen. Man könnte auch an eine Kontraktion der Spindel als Ursache denken, doch wird diese vor Beginn der Bewegung, in einigen Fällen konnte das gesehen werden, wellig, scheint sich aufzufasern und zu verschwinden. Die Bewegung des einen Kernes wird zuletzt durch die Berührung mit dem anderen gestoppt und beide pressen sich eng aneinander (Abb. 13f). Aus dem Kontakt geht nach einer halben Stunde oder mehr der eine als pyknotischer, also toter Kern hervor (siehe Abb. 9i); er ist kleiner und stärker lichtbrechend geworden und wird nun allmählich im Plasma verdaut (Abb. 13g). Etwa 21/2 Stunden nach der ersten Teilung wiederholt sich das Gleiche im zweiten mitotischen Teilungsschritt des überlebenden Kernes (Abb. 13g, $b$ ).

Welcher Kern bewegt sich und welcher geht zugrunde? Die Anaphasespindel scheint häufig einen Kern mehr oder weniger ortsfest zu lassen, den anderen aber zu verschieben. Doch kommt es auch vor, daß beide Tochterkerne gleichartig gegen den Plasmabelag bewegt werden. Für den letzten Fall existiert eine Beobachtung, nach der beide Kerne nachher auch etwa gleichmäßig aufeinander zurïcken. Nach einer ungleichen Verschiebung durch die Spindel kann aber sowohl der vorher bewegte, dieser möglicherweise häufiger, als auch der vorher ortsfeste Kern zum Wanderkern werden. Eine Beantwortung der zweiten Frage scheitert daran, daß die Kerne im „clinch" schwer zu unterscheiden sind und ihre gegenseitige Position noch ändern können. Nur in dem bereits erwähnten Fall, bei welchem beide Kerne zurückwanderten, konnte die Frage entschieden werden, aber hier ist die Antwort wegen der Symmetrie von Anaphase- und Postanaphasebewegung ohne Interesse.

Abweichend von dem geschilderten Normalverlauf für den Kernabort bei Stephanopyxis wurde einmal gesehen, daß die Pyknose bereits früh während der Rückwanderung, also auf Distanz erfolgte, worauf die Bewegung, welche in diesem Falle verzögert eingesetzt hatte, ein Ende fand. Ein anderes Mal war in der Anaphase der

Abb. 12: Kultur mit vegetativen Zellen, Spermatogonien und Oogonien (O). Sie wurde 3 Tage lang beobachtet und Veränderungen photographisch registriert. Zuletzt entwickelte sie aus den Oogonien einige Auxosporen. (Der Maßstab unten links gehört zu Abb. 13a-d)

Abb. 13: Oogon in Meiosis I und II sowie Befruchtung (im Leben), $a-d$ erste meiotische Teilang im Oogon, in $d$ nur Spindel deutlich; $e-f$ Rückwanderung der Kerne bis zum Kontakt; $g$ Eikern in Metaphase II, oben erster pyknotischer Kern; $b$ Eikern mit erstem (rechts) und zweitem pyknotischem Kern (zwischen Eikern und dem von diesem aus nach "11 Uhr" zu gelegenen Plastiden); $i$ Oogon offen, Spermium an Plasmakuppe; $j-l$ Spermakern im Ei, Beobachtungsserie; erster pylknotischer Kern: 1, zweiter pyknotischer Kern: 2, Spermakern: s. In $l$ (stärker vergröß3ert) ist der Spermakern ,gequollen ", Chromosomen als Fäden erkennbar (siehe auch $\mathrm{Abb} .9 k \mathrm{u} . l$ ), Eikern in $j-l$ an den beiden Nukleolen zu erkennen. $e-b, j, k$ gleicher Mafsstab

Abb. 14: a Zygote im Oogon kontrahiert (Maßstab wie 13i); $b$ Sie beginnt anzuschwellen, an der Epipleura (rechts) nahe der Zygote "Dritte Linie"

Abb. 15: a Maximale Schwellung der Zygote, Kern links am hypovalvaren Pol des Oogons; $b$ Auxospore mit beiden Erstlingsschalen, Auxosporenmembran rechts abgehoben, entspannt und durch die Schuppenstruktur "faltig"; $c$ 4zelliger Auxosporenkeimling, dem die Oogonschalen noch anhängen

Abb. 16: Glühpräparat von Zygote und Auxospore, in Luft, Phasenkontrast. a links und rechts Valven, dazwischen Gürtel der beiden Oogontheken mit Gürtelbandstruktur; innerhalb des Gürtels die Zygotenmembran, von der nur die Kieselschuppen erhalten sind. $b$ junge Auxospore, links Oogonepivalva und Gürtel, rechts innerhalb der Zygoten-(Auxosporen-)Membran mit Schuppenstruktur: die Erstlingsschale mit Areolennetz 


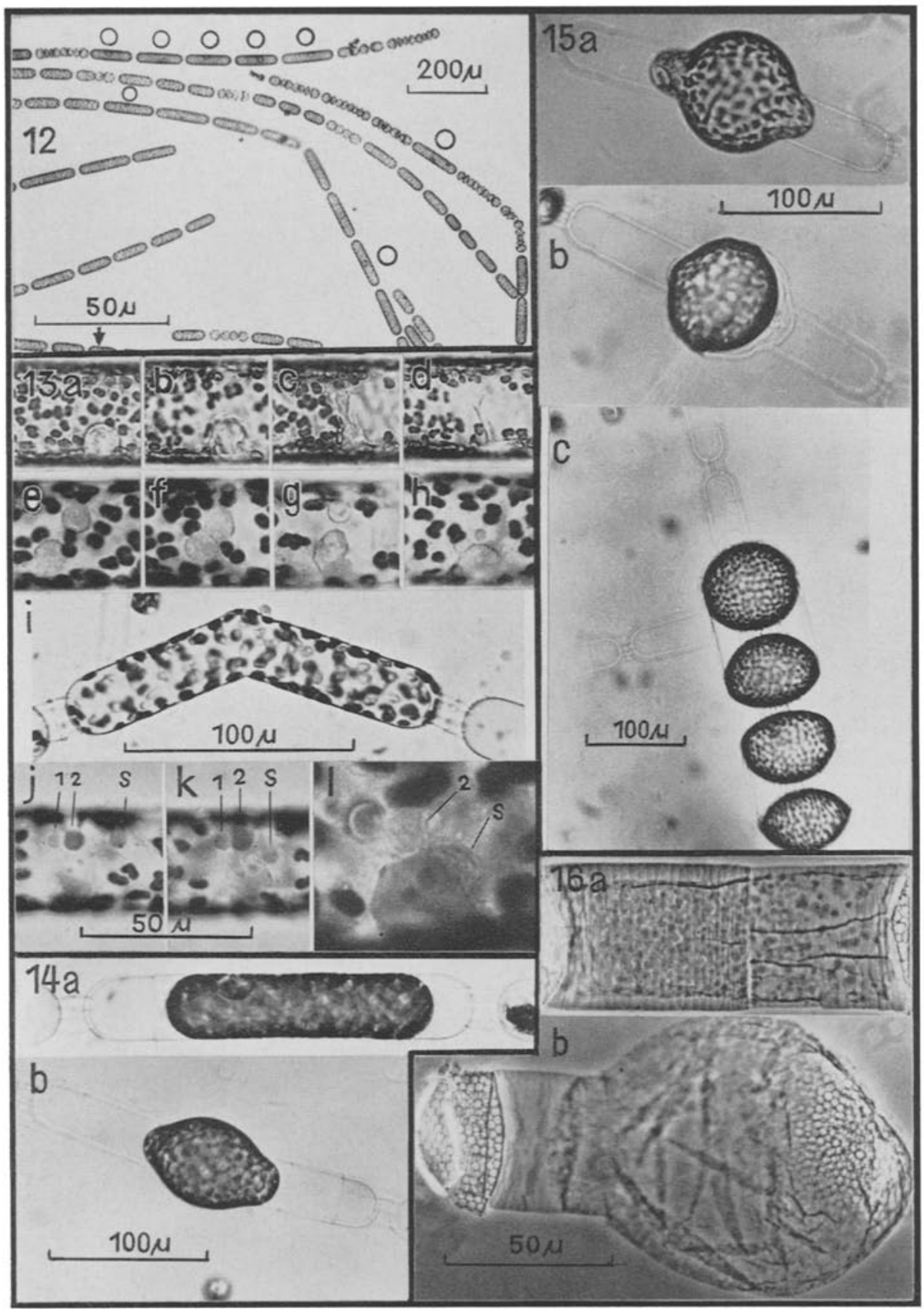


eine Kern bewegt worden; der gleiche wanderte auch stärker in das Encontre hinein. Beide Kerne blieben dann auf geringe Distanz liegen und der „Festkern“ abortierte. In einem Fall verschmolzen die beiden R II-Kerne anscheinend autogam (das weitere Schicksal ist nicht bekannt), in einem anderen gingen in Telophase I b eide Kerne zugrunde, ohne daß die Wanderung eingeleitet wurde. Das Ei war danach kernlos und blieb noch mindestens 4 Stunden am Leben; es entwickelte sich jedoch nicht weiter.

Das reife Oogon besitzt im Normalfalle einen funktionsfähigen Eikern auffallend geringen Chromatingehaltes (Abb. 9j) und zwei pyknotische Kerne verschiedener Größe. Es verlängert sich nun, nach einer Streckungsruhe von 5 bis 8 Stunden, weiter, knickt, wenn die Gürtel beider Schalen yoneinander geglitten sind (etwa 1 Stunde nach Anaphase II) leicht $a b$ und exponiert einen Bereich nackter Plasmaoberfläche, die sich aus dem sektorförmigen Schlitz etwas vorwölbt (Abb. 13i). Damit ist es befruchtungsfähig.

Soweit bekannt, existieren bei Diatomeen 3 Typen von Oogonien: 1. Oogonien mit 2 Eiern (nach der Meiosis I äquale Zytokinese, welche die beiden Eizellen trennt; nach der zweiten Teilung Kernabort in jedem Ei, so daß insgesamt 4 Kerne entstehen). Repräsentiert wird dieser Fall durch Biddulpbia mobiliensis (v. STоsсн 1954), B. granulata (v. Sтоsсн 1956), Lithodesmium undulatum (v. Sтоsсн 1954) sowie durch die oogamen Pennaten Rhabdonema arcuatum (v. STosch 1962) und $R$. minutum (v. STosch 1958). 2. Oogonien mit einem funktionierenden Ei und einem durch eine inäquale Zytokinese nach Meiose I entstehenden Richtungskörper. In beiden erfolgt dann wieder nach der zweiten Teilung Karyokinese und Kernabort (beides kann im Richtungskörper aber auch unterbleiben): Biddulpbia rbombus und Cerataulus smitbii (v. STоsch 1956) sowie die Pennaten Rbabdonema adriaticum (v. STosch 1958) und Grammatophora marina (MAGNE-Simon 1962). 3. Oogonien mit einem Ei, ohne Zytokinesen und mit Kernabort im Plasma nach jeder der beiden Kernteilungen. Diese kommen - wie bereits gezeigt - vor bei Stephanopyxis und wohl der Mehrzahl der zentrischen Diatomeen (Melosira, v. STosch 1951; Cyclotella, Gertuer 1952; Aulacodiscus argus, Actinoptychus undulatus, Bellerochea, Streptotbeca, die letzten zwei v. Stosch 1954; Coscinodiscus-Arten und Guinardia, v. Sтовсн unpubl.). Sieht man Spermatozyten und Oozyten der Diatomeen als ursprünglich homolog an, so wäre der erste Typus der primitivste, der dritte abgeleitet. Dabei wäre es durchaus denkbar, daß zunächst die Dinge nach Typ 2 ablaufen, dann die Zytokinese überhaupt unterbleibt und damit der eine Tochterkern "automatisch" im Plasma zugrunde ginge; der Mechanismus dafür wäre vorhanden, da die zweite Teilung ihn bei Typ 2 ja ohnehin betätigt. Stephanopyxis mit seiner vermutlich primitiven Dauersporenbildung und seiner mäßig abgeleiteten Spermatozytenentwidklung wäre dann in der Eientstehung recht fortschrittlich.

\section{Befruchtung und Auxosporenbildung}

Stephanopyxis ist, soweit uns bekannt, das einzige Objekt im Pflanzenreich, welches die Befruchtung einschließlich der Kernverschmelzung ungestört im Leben zu beobachten erlaubt.

Die Plasmaoberfläche an der Knidkstelle befruchtungsreifer Oogonien - manchmal auch die „Kniekehle" - wird von Spermien aufgesucht (Abb. 13i), die mit dem Hinter- 
ende zu ihr Kontakt nehmen und nun auf ihr herumrutschen, wobei die Geißel in schwacher Tätigkeit bleibt. Diese Bemühungen können längere Zeit fortgesetzt werden; manchmal erweist sich das Spermium auch dann noch nicht als fähig einzudringen und wird schließlich durch ein frisch angelocktes ersetzt, das nun rasch zum Erfolg kommt. In einem Einzelfall ( $\mathrm{Abb}$. $13 j-l$ bezieht sich auf eine andere Beobachtung) wurde ein Spermium um 21 Uhr auf der Plasmakuppe gesehen. Um 21.20 Uhr war sein Kern unter dem Plasmalemma und bewegte sich innerhalb von 3 Minuten zum in der Nähe liegenden Eikern hin, dem er sich, durch die höhere Lichtbrechung unterscheidbar, eng anpreßte. Fünf Minuten nach der Plasmafusion hatte sich die Zelle durch eine leichte Plasmakontraktion wieder geschlossen; dieser Ablauf ist typisch. Die Kernverschmelzung geht nur langsam vor sich, wobei der männliche Kern durch seine höhere Lichtbrechung und seine trotz fortschreitender Quellung gröbere Struktur (Chromosomen!) lange erkennbar bleibt (Abb. 13l). Das gefärbte Präparat (Abb. 9j-l) zeigt den praktisch chromatinfreien und mit großem Nukleolus versehenen Eikern und an ihm den nukleolenlosen, aber durch feine Chromosomenfäden chromatinreichen Spermakern. Nach etwa einer Stunde ist die Verschmelzung vollzogen, bereits vorher beginnt das Zygotenplasma sich in Fortführung der Kontraktion aus der Hypovalva zurïckzuziehen; die andere Seite folgt etwas später (Abb. 14a).

Wie Abbildung $16 a$ zeigt, ist bereits auf diesem Stadium die Befruchtungsmembran ausgeschieden. REIMANN (1961) wies als erster bei Melosira varians nach, daß die Befruchtungsmembran („Perizonium“), deren Kieselsäuregehalt bereits lange bekannt war, aus elektronenoptisch strukturierten Kieselschüppchen besteht. Diese sind anscheinend in pektinartige Substanz eingebettet. Es gelang, solche Schüppchen lichtoptisch auch bei Stephanopyxis zu erkennen - sie liegen hier verhältnismäßig entfernt voneinander - und dadurch das Vorhandensein der Befruchtungsmembran bereits vor dem Herausquellen der Zygote (Auxospore) aus dem nach der Befruchtung geschlossenen Oogon nachzuweisen. Da die Schüppchendichte in der Auxosporenmembran auch bei deren anschließendem mächtigen Wachstum (Abb. 16b) größenordnungsmäßig konstant bleibt, die Schuppenzahl sich also erhöht, muß das Wachstum unter Einschiebung neuer Kieselplättchen geschehen. Das mehr oder minder isodiametrische Dehnungswachstum einer verkieselten Membran erscheint tatsächlich nur bei derartiger Struktur und Anordnung der verkieselten Teile möglich. Der Mechanismus dürfte der einer Apposition neuer, Schuppen tragender Membranschichten unter gleichzeitiger Dehnung der alten Schichten sein. Jedenfalls wird diese Annahme durch den Aufbau der viel dickere Kohlenhydratlamellen besitzenden und ebenfalls Schuppen enthaltenden Befruchtungsmembran von Rhabdonema nahegelegt (v. STosch 1962).

Außerlich erkennbar wird die Befruchtungsmembran als Hülle der anschwellenden Auxospore (Abb. 14b). Ein Oogon war um 21 Uhr befruchtet worden; um 2 Uhr ${ }^{12}$ begann die Aufblähung der Zygotenmembran nach emeuter Streckung der Zygote im Raum zwischen den auseinandergewichenen Schalenmündungen. Der Kern hatte sich bereits vorher (01.30) in den hypovalvaren Rückzugsmeniskus begeben. Die Auxospore vergrößert sich nun rasch in ihrer Länge, zum Teil durch Dehnungswachstum,

${ }^{12}$ Die Beobachtung war bei Dauerbeleuchtung und, durch diese bedingt, vermutlich etwas erhöhter Temperatur vorgenommen worden. Ohne dieses verläuft die Entwicklung langsamer, die erste metagame Mitose finder dana erst am Nachmittag des nächsten Tages statt. 
zum Teil auch durch Absprengung von Gürtelteilen (Abb. 17) sowie in ihrer Breite. Die Zygotenmembran (v. SToscr 1962) zeichnet sich also, durch ihren Feinbau bedingt, trotz der Verkieselung durch äußerste Plastizität aus. Dieses Wachstum hat schon um 02.30 Uhr die fast endgültige Größe (ähnlich Abb. 15a) erreicht. Die umhäuteten Menisken stecken noch immer in der Schale. Doch kommt es auch vor, daß sie sich ganz aus den Mutterschalen herausziehen und die Auxospore dann völlig abgekugelt den Mündungen dieser Schalen anhängt. Um 07.50 Uhr war die metagame Mitose bereits gerade abgelaufen. Die Auxospore hatte inzwischen vollständige Kugelform erreicht.
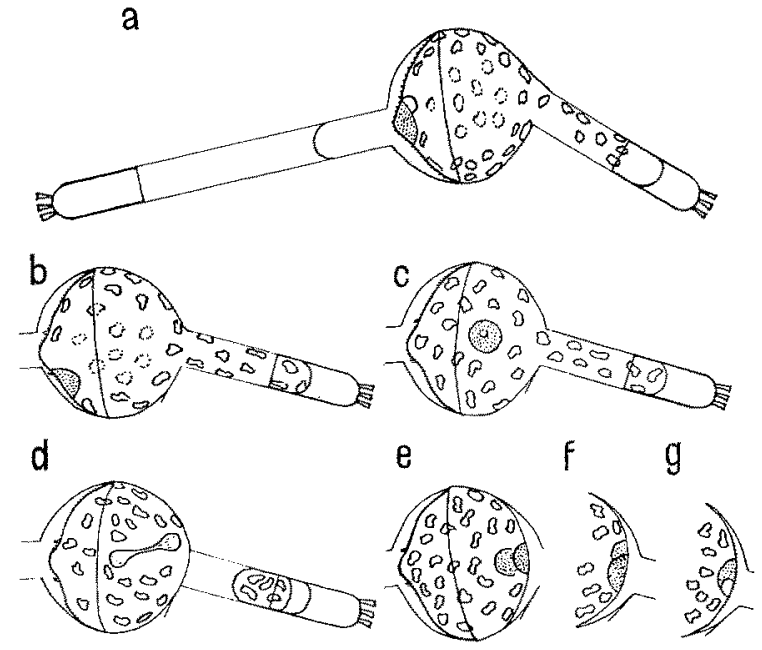

Abb. 17: Auxosporenentwicklung von Stepbanopyxis nach Protokollskizzen. Die tangentiale Linie an der Auxospore (rechts) ist durch das aufgesprengte Ende der Epipleura yerursacht. Erläuterung im Text

Hinzugefügt sei noch, daß auch das Plasma unbefruchteter Oogonien später durch Vergrößerung der ursprünglichen Empfängnisstelle sehr häufig zwischen den Schalen blasenartig hervorquillt und damn auxosporenähnliche Bilder resultieren. Naturgemäß fehlt die Auxosporenmembran. Ob diese Zustände noch befruchtungsfähig sind, bleibt zu untersuchen.

Wie Geitler (1953a) fand, geht der Bildung jeder der beiden Erstlingsschalen in der Auxospore eine azytokinetische Mitose mit anschließendem Kernabort voraus. Die erste von diesen Kernteilungen und die zugehörige Schalenbildung findet bei Stephanopyxis immer im - auf das Oogon bezogen - hypovalvaren Pol der Auxospore statt, wo, wie angegeben, der Kern bereits liegt. Diese Mitose ist von einer Spontanplasmolyse begleitet, welche innerhalb der kugelförmigen Auxospore einen Meniskus etwa von der Gestalt einer Kugelkalotte mit größerem Krümmungsradius, als ihn die Auxospore selbst besitzt, herstellt, also formbildend wirkt. An der freien Oberfläche wird danach die Schale ausgeschieden. Diese erhält die normale Areolierung, aber nur kaum. erkennbare Rudimente von Stacheln (siehe auch Abb. 16b). In Abbildung 17a ist der funktionierende sowie der nach der ersten metagamen Mitose gebildete pyknotische Kern zu erkennen. Im einzelnen wurde der Vorgang bei der zweiten metagamen Mitose 
mehrfach beobachtet und wird an einem Einzelfall geschildert (Abb. 17a-g). Um 14 Uhr begann der Kern (einer Zygote, welche etwa um 07.00 Uhr die erste metagame Mitose durchführte, s. Anm. 12, S. 247) aus seinem Ort im Zentrum der ersten Valva herauszuwandern und lag 15 Minuten später an deren Rand, den er danach überschritt. Die prophasische Streckung ist hier an einem Sichvorschieben der Erstlingsschale innerhalb der Befruchtungsmembran $\mathrm{zu}$ erkennen, wodurch das sichelförmige Areal zwischen beiden verschmälert wird, häufig auch ganz verschwindet. Um 15.05 Uhr begann die Anaphase der Kernteilung mit etwas im Winkel zur Längsachse der Auxospore gestellter Spindel, begleitet von einer erneuten, gezielten Spontanplasmolyse. Das Plasma zieht sich dabei aus der Epivalva des Oogons heraus und hält auf einer Rückzugsfläche im kugeligen Teil der Auxospore, welche Fläche der zweiten Schale der Erstlingszelle - wiederum - die Form vorschreibt (siehe auch Abb. 15b). Die Spindel beförderte den einen Kern in die Nähe des Scheitels der zukünftigen Valva. Nachdem sie aufgelöst war, wanderte auch hier ein Tochterkern auf den anderen zu, und zwar bewegte sich der vom Valvenscheitel entfernt gelegene, setzte sich neben (in der Figur unter) diesen und wurde hier - nach weiteren 40 Minuten erkennbar - pyknotisch. Zu diesem Zeitpunkt ist auch die neue, ähnlich wie die erste geformte Schale sichtbar. Hier läßt sich häufig entscheiden, welcher der beiden Kerne abortiert: Es scheint immer der zuletzt bewegte zu sein.

Bei der gleichen Auxospore wurde bereits um 21 Uhr die prophasische Streckung zur ersten Teilung der Erstlingszelle beobachtet. Vorher wird an die Epivalva eine Epipleura anormaler Struktur angesetzt ${ }^{13}$, die dann bei der Streckung der Hypopleura Führung gibt. Am anderen Morgen um 07.15 war die Zygotenmembran gesprengt, ihr Inhalt ausgeschliipft und die Zytokinese der. Erstlingszelle, die zwei normale und mit Abstandsborsten versehene Valven liefert, vollzogen. Damit ist der neue "verjüngte" (BERGON) Klon etabliert (s. a. Abb. 15c).

Eine vergleichende Betrachtung der Befruchtungsvorgänge kann sich auf den $\mathrm{Zu}$ gang für das Spermium und den Zeitpunkt der Fertilisation in der Metrik der Eientwicklung beschränken. Die Befruchtung des Diatomeeneies kann, soweit wir wissen, erfolgen, sobald der Weg zu diesem freigegeben ist, unabhängig vom zytologischen Entwicklungszustand seines Kernes als solchem, aber in den meisten Fällen abhängig von den an die meiotischen Kernprozesse gekoppelten Rhythmen von spontanen Plasmolysen, insbesondere Schwellungen des Protoplasten, von denen eine die Schale öffnend den nötigen Zugang für das Spermium schaff. Der eine bekannte Fall, in welchem der erste Teil dieser Aussage nicht anwendbar ist, wäre das Oogon von Biddulpbia rbombus (v. STosch 1956), das überhaupt keinen erkennbaren Zugang herstellt und wo das Spermium den Oogongürtel des zytologisch reifen Eies zu durchbohren scheint; eine Ausnahme zum zweiten Teil der Aussage sind die Oogone von Biddulphia mobiliensis (v. STOsch 1954) sowie B. regia, welche sich nach Ende der Reifungsteilungen spontan durch ein Auseinanderfallen der Oogonhälften und daher ohne Zuhilfenahme von Turgormechanismen öffnen. In den übrigen Fällen geschieht das Offnen des Oogons für das Spermium durch osmotisches Auseinanderzwängen der Schalen, bei Cyclotella (Geitler 1952) während der Diakinese, also im Zuge der Meiosis I-prophasischen

13 Da diese „Präpleura" erst entdeckt wurde als die Arbeit bereits im Druck war, kann über ihre Entstehung und ihren Bau Näheres noch nicht gesagt werden. 
Streckung, bei Melosira varians (v. Sтоsсн 1951) im Anschluß an die erste Telophase. Bei beiden dringt der männliche Kern dann ein und „wartet“, bis der Eikern fertiggestellt ist. Das Oogon der Melosira bildet bei seiner Streckung im Anschluß an die Diakinese keinen inneren Gürtel aus, dieses geschieht jedoch bei der verwandten Stephanopyxis; hier ist also eine erhöhte Streckung zum Auseinanderbringen der Schalen notwendig. Vielleicht wird deshalb das Oogon der letzteren mehr als einen Karyokinesezyklus später offen als das erstere, nämlich in der an Telophase II anschließenden Erholungsphase für den Turgor. Ein ähnliches postmeiotisches und osmotisches Offnen findet sich bei Lithodesmium (Entlassung von zwei nackten Eiern) und bei Streptotheca (Entlassung eines nackten Eies).

Die Auxosporen entwickeln sich bei allen Centrales unter im Prinzip denen von Stephanopyxis gleichen Formbildungsvorgängen. Insbesondere ist in einem ersten Schritt der Morphogenese das aktive und bei weniger symmetrisch gebauten Centrales auch deutlich differentielle Dehnungswachstum (z. B. v. STosch 1964) der Zygotenmembran ${ }^{14}$ verantwortlich für die Herstellung einer ersten einfachen, der späteren Erstlingszelle etwa umschriebenen Fläche, von der aus in einem zweiten Schritt die nächste Annäherung an die endguiltige Gestalt durch zwei gezielte und formbildende Plasmolysen folgt. Die letzteren sind mit je einer azytokinetischen metagamen Mitose auch ursächlich verbunden, und an jede schließt sich die Bildung einer Schale auf der geschaffenen Oberfläche an. Bei komplizierteren Valvenformen können weitere gestaltbildende Prozesse eintreten. Selbst Stephanopyxis stellt (wie die übrigen Centrales) einen Gürtel erst anläßlich der Streckung zur ersten Zellteilung der Erstlingszelle und ausgebildete Borsten noch später an dem neuen Valvenpaar dieser Teilung her. Bei den Pennaten aber trägt nicht die Zygotenmembran (diese verquillt oder zerreißt), sondern eine phylogenetische Neubildung, das - übrigens auch nicht durch Dehnung, sondern durch Anlagerung von Membranringen an den Polen wachsende - Perizonium die erste Stufe der Formbildung (v. STosch 1962), die zweite verläuft dann wieder ähnlich wie bei den Centrales.

Eine ausführliche Diskussion der azytokinetischen Karyokinesen und im Zusammenhang mit ihnen der Probleme des Kernabortes in mitotischen und meiotischen Zellen in Hinsicht auf die ihm zugeordneten inneren Bedingungen und die Frage der Auswahl unter den Kernen wurde zurückgestellt, da unser Material uns dafür noch nicht ausreichend erschien. So sind nur die Beobachtungsdaten für die Meiosis im Oogon und für die metagame Mitose wiedergegeben.

14 Wir kennen jetzt mit Sicherheit 3 Centrales (Melosira nummuloides Sippe Artern, RIETh 1953, Melosiva octogona, Drebes unpubl., Actinoptychus undulatus, Behre \& v. Stosch unpub1.), welche thre Auxosporen ohne äußere Befruchtung der Eier entwickeln oder entwickeln können, wenn auch in keinem Fall feststeht, was im Oogon eigentich passiert (dieses macht bei Actinoptychus eine bis Ende der ersten T'Teilung normale Meiosis durd). Eine völlig agame Encwidklung von Auxosporen liegt daher im Bereich des Möglichen. Das Wort "Auxosporenmembran" wäre aud einer solchen Situation angemessen, und man sollte es vielleicht in $\mathrm{Zu}$ kunft dem Terminus Zygotenmembran für deskriptive Zwecke vorziehen. 


\section{DER TURGESZENZWECHSEL DER DIATOMEEN}

Da sie einerseits in den Einzelabschnitten nicht ausreichend zu Wort kamen, andererseits über den entwicklungsmechanischen Stil der Gruppe hinaus allgemeineres Interesse finden mögen, seien noch die mit dem rhythmischen Turgeszenzwechsel der Zelle verbundenen Fragen erörtert. Sie betreffen ein auffalliges und wichtiges Moment im Formwechsel der Diatomeen.

Die Zellteilung von Stephanopyxis erwies sich als $\mathrm{F}$ u $\mathrm{rchu}$ u mit anschließsender, nahezu simultaner Neubeschalung der innerhalb der Muttermembran freigelegten Oberflächen und dürfte in ähnlicher Form (und im Gegensatz zur Darstellung MürtDORFs 1951) auch den Diatomeen mit sehr schmal einschneidender Furche, besonders also den Pennaten, zukommen. Dies ist bei Schachtelbau nicht der einzig mögliche Modus. Die Zellen der Heterokonten Tribonema scheiden vor der Teilung erst einen beiden prospektiven Töchtern gemeinsamen "Mantel" über der Schalenfuge aus und verstärken diesen im Zelläquator zu einem Ringwulst, der dann irisblendenartig geschlossen wird und eine einheitliche Querwand ergibt. Freilich geschieht dieses auf der Grundlage von polysaccharidischer Membransubstanz.

Von besonderem Interesse ist der gesetzmäßige Wechsel im Turgeszenzzustand der Zellen während der Kernzyklen, der sich bei Stephanopyxis wegen des dazu geeigneten Baues sehr auffällig zeigt, aber über das Objekt und über die Gruppe hinaus weiter verbreitet sein dürfte. Grundsätzlich gibt es im Mitosezyklus von Diatomeen (Tschermak-Woess \& Hasitschka-Jenschke 1958) zwei Schwellungsphasen des Protoplasten, die eine posttelophasisch, die andere präprophasisch, von denen je nach dem Verwandtschaftskreis entweder die erste oder die zweite von $S \mathrm{tr}$ e k u g s w a chstum (Abscheidung von Gürteln) begleitet ist. Die erste Schwellungsphase tritt bei einzelnen Arten äußerlich nicht in Erscheinung, bei anderen können beide Phasen mehr oder weniger zu einer Einheit verschmelzen (Rhabdonema; die Grünalge Microspora der österreichischen Autoren). Beide Schwellungsphasen sind im typischen Falle durch Phasen relativer oder "aktiver" Erschlaffung unterbrochen, nämlich durch den Ruhezustand der Zelle auf der einen, die Furchung oder ihr Äquivalent auf der anderen Seite des mitotischen Zyklus. Bei zahlreichen Pennaten (Pinnularia: Tschermak-Woess \& Hasitschka-Jenschke 1958; Surirella: Lauterborn 1896) sowie Centrales findet das Streckungswachstum (Streckung plus Gürtelbildung) nur posttelophasisch statt, während die vorausgegangene präprophasische Streckung den Raum für die neuen Valven schaffe. Bei Stephanopyxis und ihren Verwandten jedoch trägt die präprophasische Streckung das Wachstum und liefert und bestimmt gleichzeitig den Raum für die Valven. Der posttelophasischen Turgorzunahme kommen vielfach formbildende Funktionen bei der Modellierung der Oberfläche für die Valvenausscheidung zu.

Die von Wachstum begleitete Streckung ist in den Spezialcytokinesen, der Inäqualteilung bei der Dauersporenbildung und der Teilungen im Spermatogonangium in ihrem Ausmaß gemindert und wirkt dort als differenzierender Faktor. Ubrigens kann die Mantellänge und auf diese Art die Form der Valven auch an der vegetativen Zelle, durch das Ausmaß des Stredkungswachstums bestimmt, wechseln; die dieses regulierenden Bedingungen bleiben jedoch zu untersuchen. Als bloße Schwellung der Protoplasten wurde die prophasische Streckung (S. 243) auch vor den metagamen Mitosen festgestellt. 
Ein an die Kernphasen gekoppelter Turgeszenzwechsel konnte schließlich während der meiotischen Teilungen beobachtet werden, bei denen er für die Offnung der Gametogonien von funktioneller Bedeutung ist. In den Spermatogonangien beteiligt sich die präprophasische Streckung an der Ausschüttung der Spermatogonien, darauf sinkt mit der Annäherung an Anaphase I die Vakuole in sich zusammen; ein interphasischer oder späterer 'Turgoranstieg fehlt hier. Bei den Oogonien dagegen dauert die präprophasische Streckung bis weit in die (zeitlich und ereignismäßig verlängerte) Prophase selbst und trägt das größere Längenwachstum der weiblichen Zelle. Die Furchung danach bleibt aus, doch läßt sich die sie begleitende Erschlaffung des Protoplasten häufig in einer leichten subäquatorialen Abhebung des Wandbelags während der ersten Teilung erkennen. Die posttelophasische (II. Telophase) Schwellung stellt den Offnungsmechanismus für die Oogonien. Auf das Verhalten anderer Diatomeenoogonien im gleichen Zeitraum wurde (S. 249) bereits hingewiesen.

Voraussetzung für die Furchung ist eine Erschlaffung des Protoplasten, das Absinken des ohnehin wohl sehr geringen Turgors (siehe auch HörLer 1963, p. 27) auf Null oder sogar auf negative Werte, wenn unsere Vermutung uber die Art der Entstehung der „Dritten Linie“ (S.227) richtig ist. Daruiber hinaus muß das hydraulische System der Vakuole durch Flüssigkeitsaustritt den Wirkungen der in der Oberfläche lokalisierten Furchungskräfte sowie danach möglicherweise dem Spindeldruck nachgeben. Ahnliche Turgeszenzwechsel scheinen auch bei anderen Zytokinesen zu existieren. Bei der Furchung des Seeigeleies wird nach GEILENKIRCHEN \& ZEUTHEN (1958) ein in der Veränderung des spezifischen Gewichtes nachgewiesener Wassereinstrom während Ana- und Telophase gestoppt, danach wieder aufgenommen. Die Verursachung des Flüssigkeitsverlustes bei Stephanopyxis bleibt unbekannt (S. 226); in diesem Zusammenhang interessiert, daß STERN (1948) in Trillium-Mikrosporen eine Erhöhung der Zuckerpermeabilität während der Mitose fand und daßs nach Hörler (1936) nur die sich teilenden Zellen von Biddulphia titania, einer Hypotonie unterworfen, am Leben bleiben. Ein totales Undichtwerden des Plasmaschlauches ist jedoch bei Diatomeen nicht anzunehmen, da Anhäufungen des in der Vakuole gelösten Leucosins in keimenden Dauersporen (S.233) für 2, bei vegetativen Zellen von Biddulphia regia sogar für 3 Teilungswellen im Dunkeln ausreichten, das Assimilat also erhalten bleiben muß. Immerhin treten, wie auf S. 223 angegeben, bei der Furchung organische Stoffe aus.

Die Erschlaffung scheint im übrigen an die Kernphase gebunden, unabhängig davon, ob eine Furchung erfolgt oder nicht. Sie findet sich nämlich auch bei den azytokinetischen Karyokinesen, in der Meiosis, bei "Häutungen" und insbesondere bei den beiden metagamen Mitosen in der Auxospore, die jede von einer kernseitigen und gezielten Spontanplasmolyse begleitet werden. Und das GeItLersche Gesetz von der Abhängigkeit der Schalenbildung von einer Karyokinese möchte in dieser zellmechanischen Voraussetzung zur Herstellung nackter Plasmaoberflächen sogar seinen Grund haben.

Auf die komplizierten und dem speziellen Einfluß der beteiligten Komponenten nach zur Zeit recht undurchsichtigen Interrelationen zwischen Streckung, Wandhaftung, Muster der Furchungskräfte, Spindeldruck und posttelophasischer Deplasmolyse bei der Formbildung der Valven (S. 226-229) braucht nicht noch einmal eingegangen zu werden. Bezogen auf den Turgeszenzwechsel der Zelle erfolgt die Schalenbildung der 
Arten zu etwas verschiedenem Zeitpunkt: Bei Surirella (LAUTERBorn 1896) bereits am Ende der anaphasisch-telophasischen Erschlaffung, die hier die ursprünglich schmale Furche gezielt erweitert und damit gewölbte Schalen schaff; bei Pinnularia (LAUTERBORN 1896) fehlt die Verbreiterung, und es entstehen flache Valven.

Stephanopyxis schließlich formt die Schalen nach der posttelophasischen Schwellung aus, welche, wie bereits geschildert (S. 226), die endgültige Gestalt der Menisken, der Matritzen für die Valvensekretion herstellt; in noch stärkerem Maße tritt diese Schwellung bei Guinardia (S. 223) und Rbizosolenia (SснÜтт 1900) ein.

\section{ZUSAMMENFASSUNG}

1. Die Entwicklung von Stephanopyxis turris sowie die zu ihrer Untersuchung geeigneten Methoden werden beschrieben und diskutiert.

2. Der vollständige Lebenszyklus einer zentrischen Diatomee nach Beobachtungen im Leben und mit den Grundzügen der zugehörigen Karyologie in Mitose, Meiosis, Befruchtung und Auxosporenbildung sowie Entstehung und Keimung der Dauersporen wird erstmalig dargestellt (Abb. 18).

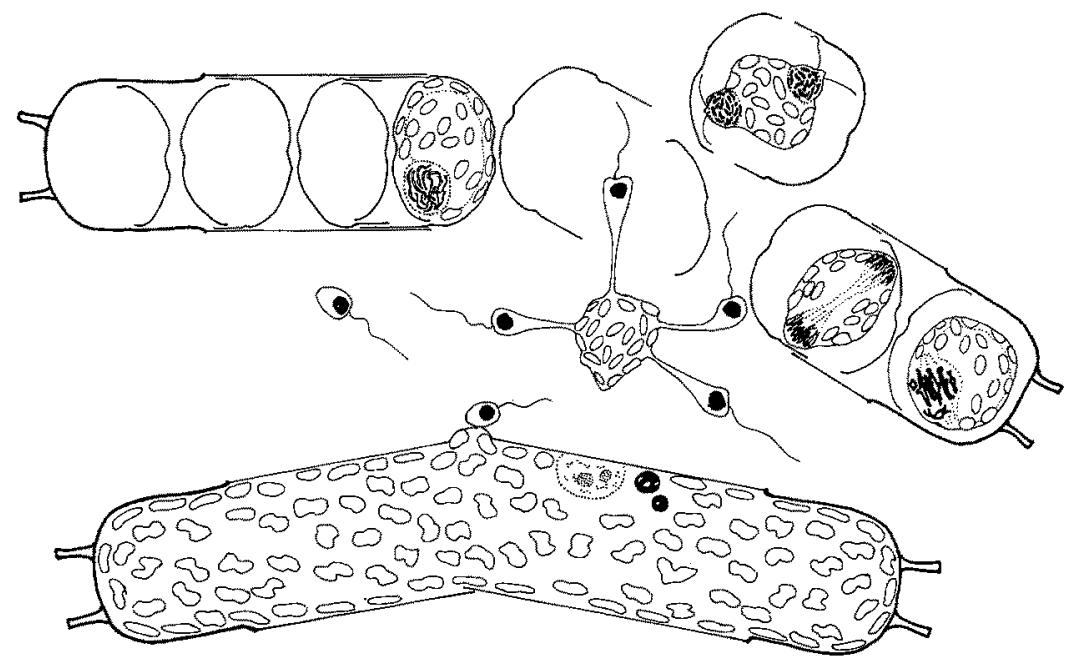

Abb. 18: Sexualorgane von Stephanopyxis turris schematisch. Oben: Spermatogonangium geöffnet, an den drei ersten Spermatogonien von links nur die Schalen gezeichnet; es folgt eine Zelle im Pachytän. Im anderen Halbspermatogonangium von rechts nach links: Metaund Anaphase I, Interkinese mit den paarweise auswachsenden Geißeln und schließlich, bereits aus den Schalen befreit, eine Tetrade in Ablösung der Spermien vom plasmatischen Restkörper, welcher die Plastiden zurückbehält. Unten: Befruchtungsreifes, geöffnetes Oogon, mit Eikern und zwei pyknotischen Kernen sowie einem Spermium an der freigelegten Plasmaoberfläche

3. Neuartige Beobachtungen betreffen Kollaps, "Blitztod" und Lichtresistenz, die "Dritte Linie“, die Darstellung von Kern und Spindel in Mitose und Meiosis sowie die mit Kernkonkurrenz abschließenden acytokinetischen Karyokinesen in Oogon 
und Auxospore im Leben, die Keimung der Dauersporen, den lichtmikroskopischen Nachweis der Kieselschuppen in der Auxosporenmembran.

4. Die Entwicklungsvorgänge werden vergleichend diskutiert und dabei die Termini "depauperierende Teilung" und "heterovalvate Zytokinese" in Vorschlag gebracht.

5. Weitere Uberlegungen gelten dem cyclischen Turgeszenzwechsel der Diatomeenzelle.

6. Die Methode der "Vegetativen Zellvergrößerung“ erlaubt es, Stephanopyxis-Klone beliebiger Breite aber unveränderten Genotypus für das Experiment bereitzustellen.

Unseren Helfern und Mitarbeitern am Institut danken wir vieles: Fräulein G. THeIL die unermüdliche Fürsorge für die Kulturen, ihr und Herrn R. ScHÄFER photographische Arbeiten aller Art, Fräulein H. BIEDERBECK die Übertragung des Manuskriptes und Herrn Graphiker H. BECKER Umzeichnungen einiger Abbildungen. Die Deutsche Forschungsgemeinschaft unterstützt unsere Arbeiten seit vielen Jahren.

\section{ZITIERTE LITERATUR}

Beattie, A., Hirst, E. L., \& Percival, E., 1961. Studies on the metabolism of the Chrysophyceae. Comparative structural investigations on leucosin (chrysolaminarin) separated from diatoms and laminarin from the brown algae. Biochem. J. 79, 531-537.

Belar, K., 1922. Untersuchungen an Actinophrys sol Ełrenderg. 1. Die Morphologie des Formwechsels. Arch. Protistenk. 46, 1-96.

- 1929. Beiträge zur Kausalanalyse der Mitose. 2. Untersuchungen an den Spermatozyten von Chorthippus lineatus. Arch. EntwMech. Org. 118, 354-480.

BERGon, P., 1902. Etudes sur la flore diatomique du bassin D'Arcachon, et des parages de L'Atlantique voisins de cette station. Trav. Lab. Arcachon. 6, 39-112.

- 1905. Note sur certaines particularités remarquables observées chez quelques espèces de diatomées du Bassin d'Arcachon. J. Microgr. gén. (Microgr. préparat.) 13, 251-259.

- 1907. Biologie des diatomées. - Les processus de division, de rajeunissement de la cellule et de sporulation dez le Biddulphia mobiliensis Balley. Bull. Soc. bot. Fr. 54, 327-357.

Bruckmayer-Berkensursch, H., 1954. Die Beeinflussung der Auxosporenbildung von Melosira nummuloides durch Außenfaktoren. Arch. Protistenk. 100, 183-211.

Bünning, E., 1935. Zellphysiologische Studien an Meeresalgen. Protoplasma 22, 444-456.

- 1963. Die physiologische Uhr. 2. Aufl. Springer, Berlin, 153 pp.

- \& Mülier, D. G., 1961. Wie messen Organismen lunare Zyklen? Z. Naturf. (B) 16, 391-395.

Casste, V. \& Bertraud, W. S., 1960. Electron microscope studies of New Zealand marine plankton diatoms. J. r. micr. Soc. 79, 89-94.

Cholnoky, B. V., 1933. Die Kernteilung von Melosira arenaria nebst einigen Bemerkungen über ihre Auxosporenbildung. Z. wiss. Biol. (B) Zellforsch. mikrosk. Anat. 19, 698-719.

Chow, D. T. W. \& Robinson, R. J., 1953. Forms of silicate available for colorimetric determination. Analyt. Cbem. 25, 646-650.

Conard, A., 1929. Sur la division cellulaire chez Melosira varians Ag. C. $r$. Soc. Biol., Paris 102, 954-957.

COOPER, L. H. N., 1948. Some chemical considerations on the distribution of iron in the sea. J. Mar. biol. Ass. U. K. 27, 314-321.

Droop, M. R., 1960. Some chemical considerations in the design of synthetic culture media for marine algae. Botanica mar, 2, 231-246.

Droop, M., 1962a. Organic micronutrients. In: Physiology and biochemistry of algae. Ed. by R. A. Lewin, Acad. pr., New York, 141-159.

- 1962b. On cultivating Sceletonema costatum; some problems. Vortr. Gesamtgeb. Bot. N. F. $1,77-82$.

ERBEN, K., 1959. Untersuchungen über Auxosporenentwicklung und Meioseauslösung an $\mathrm{Me}$ losira nummuloides (Drulw.) C. A. Agardh. Arch. Protistenk. 104, 165-210. 
Geilenkirchen, W. L. M. \& Zeuthen, E., 1958. Changes in submerged (reduced) weight associated with cell division in echinoderm eggs. C. r. Trav. Lab. Carlsberg (phys.) 31, $7-28$.

Gertrer, L., 1932. Der Formwechsel der pennaten Diatomeen (Kieselalgen). Arch. Protistenk. $78,1-226$.

- 1952. Oogamie, Mitose, Meiose und metagame Teilung bei der zentrischen Diatomee $C y$ clotella. Öst. bot. Z. 99, 506-520.

- 1953a. Das Auftreten zweier obligater metagamer Mitosen ohne Zellteilung während der Bildung der Erstlingsschalen bei den Diatomeen. Ber, dt. bot. Ges. 66, 222-227.

- 1953b. Abhängigkeit der Membranbildung von der Zellteilung bei Diatomeen und differentielle Teilungen bei der Bildung der Innenschalen. Planta 43, 75-82.

- 1956. Automixis, Geschlechtsbestimmung Pyknose von Gonenkernen bei Cymbella aspera. Planta 47, 359-373.

1957. Die sexuelle Fortpllanzung der pennaten Diatomeen. Biol. Rev. 32, 261-295.

- 1963. Alle Schalenbildungen der Diatomeen treten als Folge von Zell- oder Kernteilungen. auf. Ber, dt. bot. Ges. 75, 393-396.

Gran, H. H., 1900. Diatomaceae from the ice-floes and plankton of the Arctic Ocean. In; Scientific results. Norweg. North Polar Exped. 1893-1896. Ed. by F. Nansen. Brogger, Christiana, Bd. 4, Nr. 11, 748 pp.

- \& ANgst, E. C., 1931. Plankton diatoms of Puget Sound. Publ. Puget Sound Biol. Sta. 7, $417-515$.

Gross, F., 1937. On the life histories of some marine plankton Diatoms. Pbil. Trans. (B) 228, $1-47$.

- 1939a. The development of isolated resting spores into auxospores in Ditylum Brightwelli WEST. J. Mar. biol. Ass. U. K. 24, 375-380.

- 1939b. The osmotic relations of the plankton diatom Ditylum Brightwelli West. J. Mar. biol. Ass. U. K. 24, 381-414.

HaRVEY, H. W., 1939. Substances controlling the growth of a diatom. J. Mar. biol. Ass. U. K. 23, 499-520.

- 1960. The chemistry and fertility of sea waters. 2 nd. ed. Univ. pr., Cambridge, 234 pp.

Hofker, J., 1930. Die Teilung, Mikrosporen- u. Auxosporenbildung von Coscinodiscus biconicus VAN BREemen. Annls Protist. 1, 167-194.

Höfler, K., 1963. Zellstudien an Biddulpbia titiana Grunow. Protoplasma 56, 1-53.

Hustedt, F., 1930. Die Kieselalgen. T. 1. In: L. Rabenhorst's Kryptogamenflora von Deutschland, Osterreich und der Schweiz. Akad. Verl. Ges., Leipzig, Bd 7, 920 pp.

Hutner, S. H., Provasoli, L., Schatz, A. \& Haskins, C. P., 1950. Some approaches to the study of the role of metals in the metabolism of microorganisms. Proc. Am. pbil. Soc. 94, $152-170$.

IKari, J., 1923. On the nuclear and cell division of a plankton diatom Coscinodiscus subbuliens Jörgensen. Bot. Mag. 37, 96-108.

JøRGENSEN, E. G., 1955. Variations in the silica content of diatoms. Pbysiol. plant. 8, 840-845.

Kramer, D. D. \& Ryther, J. H., 1960. The iron requirement of some marine plankton algae. Biol. Bull. mar. biol. Lab., Woods Hole 119, 324.

LAUTERBoRn, R., 1896. Untersuchungen über Bau, Kernteilung und Bewegung der Diatomeen. Engelmann, Leipzig, $165 \mathrm{pp}$.

LEWIN, J. C., 1955. Silicon metabolism in diatoms. 2. Sources of silicon for growth of Navicula pelliculosa. Plant Physiol. 30, 129-134.

- 1957. Silicon metabolism in diatoms. 4. Growth and frustule formation in Navicula pelliculosa. Can. J. Microbiol. 3, 427-433.

- 1962. Silification. In: Physiology and biochemistry of algae. Ed. by R. A. Lewin. Acad. pr., New York, 445-455.

Lewin, R. A., 1958 Phytoflagellates and algae. In: Handbuch der Pflanzenphysiologie. Hrsg. von W. Ruhland (u. a.). Springer, Berlin, Bd. 14, 1-16.

MaCDonald, J. D., 1869. On the structure of the diatomaceous frustule, and its genetic cycle. Ann. Mag. nat. Hist. Ser. 4. Nr. 13, 1-8. 
MAgne-Simon, M. F., 1962. L'auxosporulation chez une tabellariacée marine Grammatophora marina (Lyngb.) Kütz, (Diatomée). Cah. Biol. mar. 3, 79-89.

Meunier, A., 1915. Microplankton de la Mer Flamande. Mém. Mus. r. Hist. nat. Belg. 7 (2), $1-58 ; 31-118$.

Mrchallova, N. F., 1962. On the germination of resting spores of Chaetoceros lauderi Ralfs. Dokl. Akad. Nauk SSSR 143, 741-742.

Mrchel, K., 1950. Die Grundlagen der Theorie des Mikroskops. Wiss. Verl. Ges., Stuttgart, $314 \mathrm{pp}$.

MünLdorr, A., 1951. Die Zellteilung als Plasmateilung. Springer, Wien, 194 pp.

Müller, O., 1900. Kammern und Poren in der Zellwand der Bacillariaceen. 4. Ber, dt. bot. Ges. 19, 195-210.

Murray, G., 1897. On the reproduction of some marine diatoms. Proc. R. Soc. Edinb. 21, 207-219.

Ostenfeid, C., 1901. Iagttagelser over Plankton-Diatomeer. Nyt Mag. Naturvid. 39, 286 bis 302.

Pavillard, M. J., 1914. Observations sur les diatomées. Bull. Soc. bot. Fr. 61, 164-172.

Peragallo, H., 1907. Sur la division cellulaire du Biddulpbia mobiliensis. Trav. Lab. Arcachon $10,329-356$.

PetTzer, E., 1871. Untersuchungen über Bau und Entwicklung der Bacillariaceen (Diatomaceen). J. Hanstein's Bot. Abh. Morphol. Physiol. (Bonn), 1, 1-189.

PRAMER, D., 1957. The influence of physical and chemical factors on the preparation of silica gel media. Appl. Microbiol. 5, 392-395.

Provasoli, L., Mclaughein, J. J. A. \& Droop, M. R., 1957. The development of artifical media for marine algae. Arch. Mikrobiol. 25, 392-428.

Reimann, B., 1960. Bildung, Bat und Zusammenhang der Bacillariophyceenschalen. Nova Hedwigia 2, 349-373.

Reumuth, H. \& Loske, T., 1962. Küvettenmikroskopie in Biologie und Technik. Mikroskopie $17,149-178$.

Rieth, A. \& Stosch, H. A. v., 1954. Der Kapillarheber, ein Bauelement zur Herstellung von Durchströmungspräparaten. Protoplasma 44, 363-365.

Sснмпт, P., 1927. Weiteres über die Fortpflanzung der Diatomee Biddulphia sinensis. Internat. Rev. ges. Hydrobiol. 18,400-414,

Schrenber, E., 1928. Die Reinkultur yon marinem Phytoplankton und deren Bedeutung für die Erforschung der Produktionsfähigkeit des Meerwassers. Wiss, Meeresunters. Abt. Helgol. $16,1-34$.

ScHürT, F., 1888. Über die Diatomeengattung Chaetoceros. Bot. Ztg 46, 161-170.

- 1900. Centrifugale und simultane Membranverdickungen. Jb. wiss. Bot, 35, 470-534.

Stinell, B. M. \& Loveland, R. P., 1958. Optics of the object space in microscopy. J. r. micr. Soc. 78, 59-80.

STERN, H., 1948. Protoplasmatic changes during nuclear division in pollen mother-cells and Microspores of Trillium erectum. Plant. Pbysiol. 23, 388-396.

Sтоsсн, H. A. v., 1942. Form und Formwechsel der Diatomee Achnanthes longipes in Abhängigkeit von der Ernährung. Mit besonderer Berücksichtigung der Spurenstoffe. Ber, dt. bot. Ges. 60, 2-15.

- 1951. Entwidklungsgeschichtliche Untersuchungen an zentrischen Diatomeen. 1. Die Auxosporenbildung von Melosira varians. Arch. Mikrobiol. 16, 101-135.

- 1952. Die Verwendung von Chloralhydrat oder Phenol zur Aufhellung und von PhenolBalsam als Einschlußmittel für Essigkarminpräparate. Zücbter 22, 265-272.

- 1954a. Die Oogamie von Biddulphia mobiliensis und die bisher bekannten Auxosporenbildungen bei den Centrales. Rapp. Comm. Bième Congr, int. bot. (Sect.) 17, 58-68.

- 1954b. Eine Kammer für mikroskopische Lebenduntersuchungen mit Trennung von Objekt und strömendem Medium. Protoplasma 44, 365-368.

- 1956. Entwicklungsgeschichtliche Untersuchungen an zentrischen Diatomeen. 2. Geschlechtszellenreifung, Befruchtung und Auxosporenbildung einiger grundbewohnender Biddulphiaceen der Nordsee. Arcb. Mikrobiol. 23, 327-365. 
- 1958a. Kann die oogame Arhaphidee Rhabdonema adriaticum als Bindeglied zwischen den beiden großen Diatomeengruppen angesehen werden? Ber. dt. bot. Ges. 71, 241-249.

- 1958b. Entwicklungsgeschichtliche Untersuchungen an zentrischen Diatomeen. 3. Die Spermatogenese von Melosira moniliformis AGardz. Arch. Mikrobiol. 31, 274-282.

- 1962. Über das Perizonium der Diatomeen. Vortr. Gesamtgeb. Bot. Nat. 1, 43-52.

- 1965. Manipulierung der Zellgröße von Diatomeen im Experiment. Pbycologia (im Druck).

SUBRAHMANYAN, R., 1946. On the occurence of microspores in some centric diatoms of the Madras Coast. J. Ind. Bot. Soc. 25, 61-66.

TSChermak-Woess, E. \& HastTschKa-Jenschie, G., 1958. Ober das interphasische Kern- und Zellwachstum. Öst. bot. Z. 104, 382-408.

WARIS, H., 1953. The significance for algae of chelating substances in the nutrient solutions. Pbysiol. Plant. 6, 538-543. 